NATIONAL LABORATORY

\title{
Progress Report on The Mechanical Testing and Thermal Aging of Zr- Bearing Ferritic Steels
}

September 2013

\author{
Prepared by \\ L. Tan and Y. Yang \\ Oak Ridge National Laboratory
}

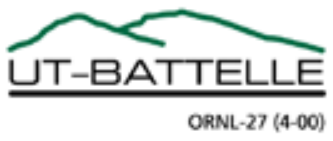




\section{DOCUMENT AVAILABILITY}

Reports produced after January 1, 1996, are generally available free via US Department of Energy (DOE) SciTech Connect.

Website http://www.osti.gov/scitech/

Reports produced before January 1, 1996, may be purchased by members of the public from the following source:

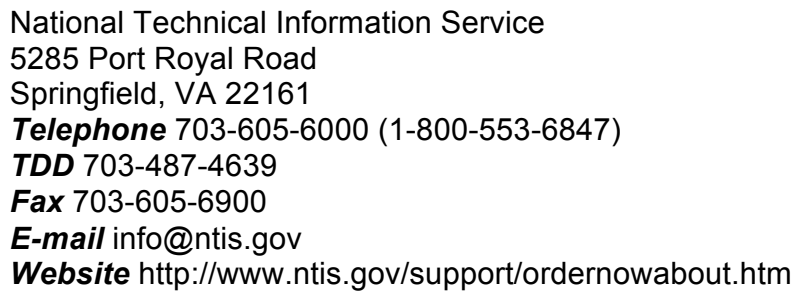

Reports are available to DOE employees, DOE contractors, Energy Technology Data Exchange representatives, and International Nuclear Information System representatives from the following source:

Office of Scientific and Technical Information

PO Box 62

Oak Ridge, TN 37831

Telephone 865-576-8401

Fax 865-576-5728

E-mail reports@osti.gov

Website http://www.osti.gov/contact.html

This report was prepared as an account of work sponsored by an agency of the United States Government. Neither the United States Government nor any agency thereof, nor any of their employees, makes any warranty, express or implied, or assumes any legal liability or responsibility for the accuracy, completeness, or usefulness of any information, apparatus, product, or process disclosed, or represents that its use would not infringe privately owned rights. Reference herein to any specific commercial product, process, or service by trade name, trademark, manufacturer, or otherwise, does not necessarily constitute or imply its endorsement, recommendation, or favoring by the United States Government or any agency thereof. The views and opinions of authors expressed herein do not necessarily state or reflect those of the United States Government or any agency thereof. 
ORNL/TM-2013/360

Nuclear Energy Enabling Technologies (NEET)

\section{PROGRESS REPORT ON THE MECHANICAL TESTING AND THERMAL AGING OF ZR-BEARING FERRITICS STEELS}

L. Tan and Y. Yang

Date Published: September 2013

Prepared by

OAK RIDGE NATIONAL LABORATORY

Oak Ridge, Tennessee 37831-6283

managed by

UT-BATTELLE, LLC

for the

U.S. DEPARTMENT OF ENERGY

under contract DE-AC05-00OR22725 
This page intentionally left blank 


\section{CONTENTS}

Page

LIST OF FIGURES

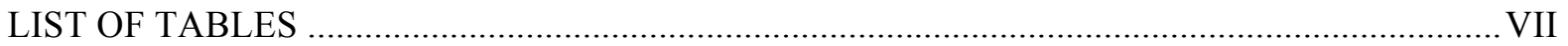

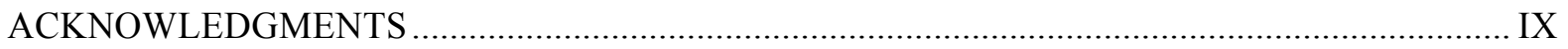

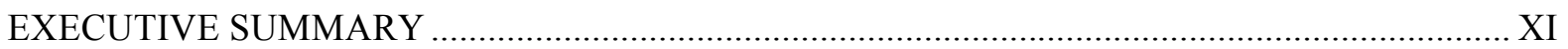

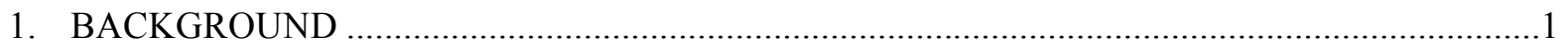

2. THERMODYNAMIC MODELING OF THE FE-C-CR-MO-NB-TI-W-ZR SYSTEM .................3

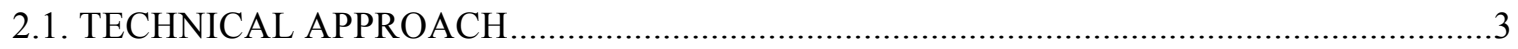

2.2. THERMODYNAMIC MODELING OF THE FE-ZR BINARY SYSTEM …........................

2.3. THE CURRENT STATUS OF THE FE-C-CR-MO-NB-TI-W-ZR SYSTEM ..........................

3. DESIGN AND FABRICATION OF ZR-BEARING FERRITIC ALLOYS AND

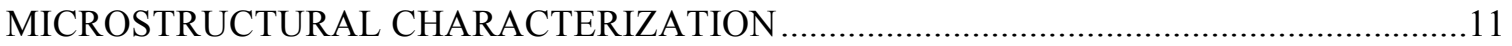

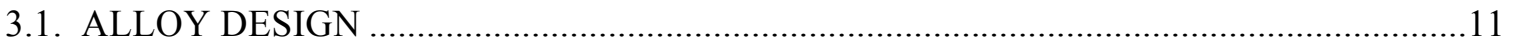

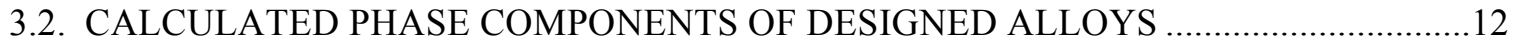

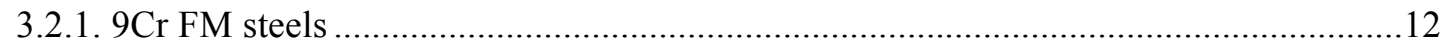

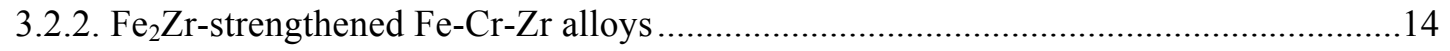

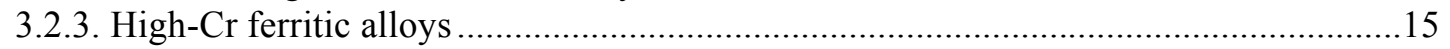

3.2. ALLOY FABRICATION, THERMAL AND MECHANICAL TREATMENT …...............17

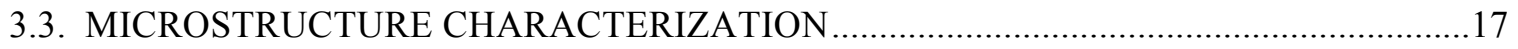

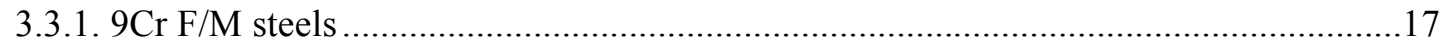

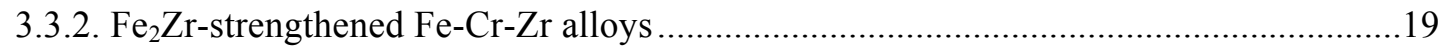

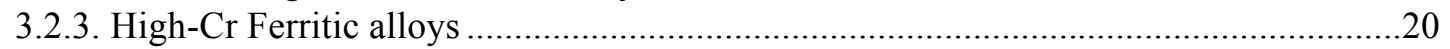

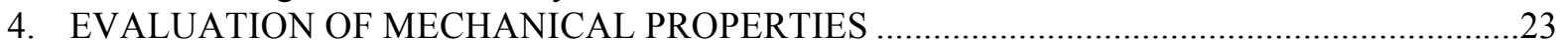

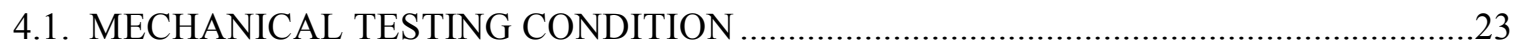

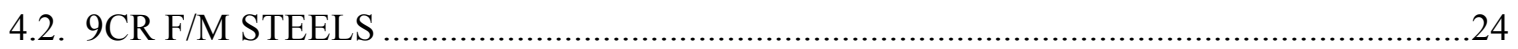

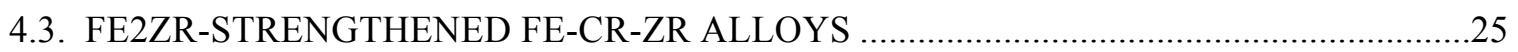

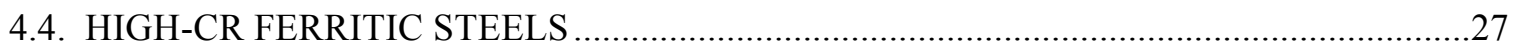

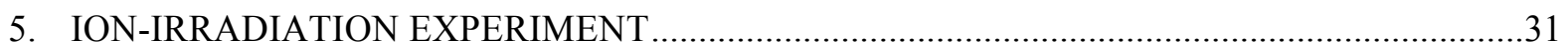

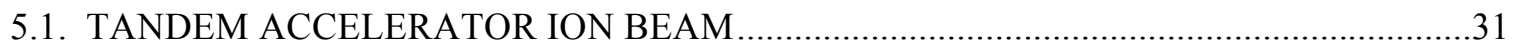

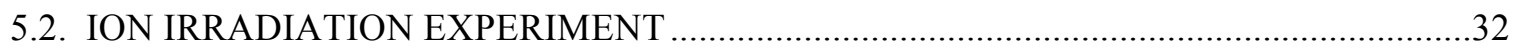

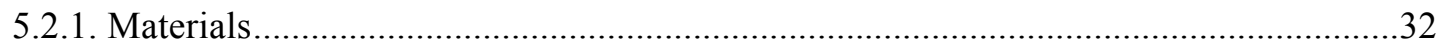

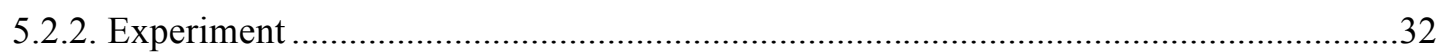

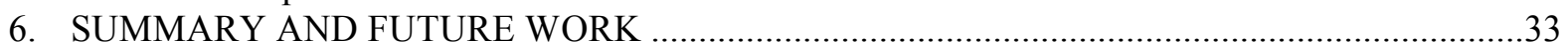

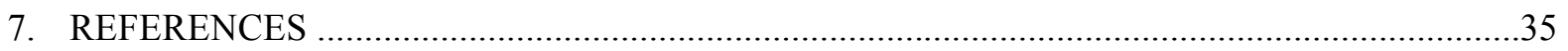


This page intentionally left blank 


\section{LIST OF FIGURES}

Figure $\quad$ Page

Fig. 1. Flowing chart of developing a thermodynamic description of a multicomponent system........ 4

Fig. 2. Calculated Fe-Zr binary phase diagram compared with experimental data from Stain et al.

[15]. The element in bold font in $\beta(\mathrm{Fe}, \mathrm{Zr})$ phase denotes the major species. ......................... 6

Fig. 3. Calculated enthalpy of mixing of liquid compared with experimental data [16-19]............. 6

Fig. 4. Calculated mole fraction of phases as a function of temperature in alloys Z1, Z2, T3, and P92.

Fig. 5. Calculated mole fraction of phases as a function of temperature in alloys Z3, Z4 and Z5.... 15

Fig. 6. Calculated temperature-dependent mole fraction of phases in alloys LT1, LZ1, LTZ1, and LNTZ.

Fig. 7. Secondary electron images of alloys $Z 1$ and $Z 2$ in normalization and tempering condition. . 18

Fig. 8. Bright- and dark-filed images and corresponding diffraction pattern of alloy Z1 under water quenched and tempered conditions.

Fig. 9. Optical images of the (a) as-fabricated and (b) retreated alloy T3 ...................................... 19

Fig. 10. Backscattered electron images of Z3, Z4 and Z5 in hot-forged condition............................ 19

Fig. 11. Optical images of Z3, Z4 and Z5 in the as-received (AR) state and after thermal aging at

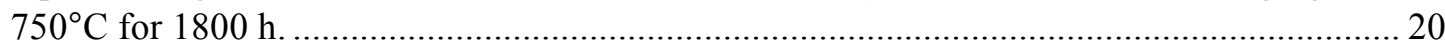

Fig. 12. Optical images of LT1, LZ1, and LTZ1 in the as-received (AR) condition........................ 21

Fig. 13. Optical image of a sample extracted from the as-fabricated heat LNTZ ............................ 21

Fig. 14. Specification of type SS-3 specimen.......................................................................... 23

Fig. 15. Temperature-dependent yield stress, uniform and total elongations of alloys Z1 and T3 compared to reported data of P91, P92, and Gr92 .......................................................... 25

Fig. 16. Vickers microhardness of alloys Z3, Z4, and Z5 in the as-received and aged conditions...... 25

Fig. 17. Temperature-dependent yield stress and total elongation of alloys Z3, Z4, and Z5 ............ 26

Fig. 18. Creep curves of alloys Z3, Z4, Z5 compared to G92 tested at $600^{\circ} \mathrm{C}$ and $260 \mathrm{MPa}$............. 27

Fig. 19. Dark-field TEM images of alloy LT1 in the AR and TMT (LT1C15) conditions. ................ 28

Fig. 20. Temperature-dependent yield stress and total elongation of alloys LT1 and LTZ1 in the AR

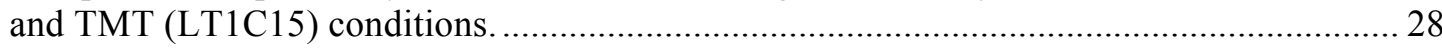

Fig. 21. Aggregated Zr-rich oxides/nitrides inclusions in LTZ1C15 sample................................... 29

Fig. 22. Proton irradiation sample stage, capable of hosting disc shaped specimens. ...................... 31

Fig. 23. Damage and proton distributions in Fe-15Cr-3W-1.4Ti irradiated with $1 \mathrm{MeV}$ p to a damage level of $1 \mathrm{dpa}$ at $10 \mu \mathrm{m}$. Calculations were performed using SRIM-2012.03 assuming the displacement threshold energies to be $40 \mathrm{eV}$ for all elements. 
This page intentionally left blank 


\section{LIST OF TABLES}

\section{Table}

Page

Table 1. Phase name, crystallography, and thermodynamic models 5

Table 2. Invariant reactions in the Fe-Zr system

Table 3. Calculated enthalpies of formation of compounds in the Fe-Zr system compared with literature data ("C"C: Calphad modeling; "a" ab-initio calculation)

Table 4. The status of binary systems in the Fe-C-Cr-Mo-Nb-Ti-W-Zr system

Table 5. The status of ternary systems in the Fe-C-Cr-Mo-Nb-Ti-W-Zr system

Table 6. The status of MC forming ternary systems (without $\mathrm{Fe}$ ) in the $\mathrm{Fe}-\mathrm{C}-\mathrm{Cr}-\mathrm{Mo}-\mathrm{Nb}-\mathrm{Ti}-\mathrm{W}-\mathrm{Zr}$ system

Table 7. Composition (wt.\%) of designed Zr-bearing ferritic alloys with $\mathrm{Fe}$ as balance

Table 8. Chemical analysis results of $\mathrm{C}, \mathrm{O}, \mathrm{N}$, and $\mathrm{S}$ (wt.\%) in the high-Cr ferritic steels

Table 9. Processing of the designed alloys

Table 10. Vickers microhardness of alloys Z1, Z2 and T3 
This page intentionally left blank 


\section{ACKNOWLEDGMENTS}

This research was sponsored by the U.S. Department of Energy, Office of Nuclear Energy, for the Nuclear Energy Enabling Technologies (NEET) Program. We gratefully acknowledge the support provided by Sue Lesica of DOE-NE and Jeremy Busby of ORNL. The Shared Research Equipment (ShaRE) User Facility at ORNL was used to obtain the microstructural characterization results.

The authors are grateful to Todd Allen, Kumar Sridharan, and Beata Tyburska-Püschel for their helpful discussions and initiating proton irradiation study, a key component of this project, and Eric Manneschmidt, Tom Geer, David Harper, and Greg Cox for their technical support throughout the project. 
This page intentionally left blank 


\section{EXECUTIVE SUMMARY}

The mission of the Nuclear Energy Enabling Technology (NEET) program is to develop cross-cutting technologies for nuclear energy applications. Advanced structural materials with superior performance at elevated temperatures are always desired for nuclear reactors, which can improve reactor economics, safety margins, and design flexibility. They benefit not only new reactors including advanced light water reactors (LWRs) and fast reactors such as sodium-cooled fast reactor (SFR) primarily designed for management of high-level wastes, but also the extension of the existing fleet when component exchange is needed. Developing and utilizing the modern materials science tools (experimental, theoretical, and computational tools) is an important path to more efficient alloy development and process optimization.

Ferritic-martensitic (FM) steels are important structural materials for nuclear reactors due to their advantages over other applicable materials like austenitic stainless steels, notably a resistance to void swelling, low thermal expansion coefficients, and higher thermal conductivity. However, the designed application temperatures of the current $9 \mathrm{Cr}$ FM steels like Grade 92 are below $620^{\circ} \mathrm{C}$ (even lower for Grade 91) due to insufficient high-temperature creep strength, which limits their applications in advanced nuclear reactors with target operating temperatures at $650^{\circ} \mathrm{C}$ or higher. Although oxide-dispersion-strengthened (ODS) ferritic steels have excellent high-temperature performance, their extremely high cost, limited size and fabricability of products, as well as great difficulty with welding and joining, have limited or precluded their commercial applications. The ultimate goal of this project is, with the aid of computational modeling tools, to accelerate the development of a new generation of Zr-bearing ferritic steels with enhanced high-temperature performance greater than Grade 92 and close or comparable to ODS ferritic steels.

To facilitate the development of Zr-bearing ferritic steels, a thermodynamic database of Fe-C-Cr-Mo$\mathrm{Nb}-\mathrm{Ti}-\mathrm{W}-\mathrm{Zr}$ has been developed in this study. The developed computational thermodynamics tool helped designing Zr-bearing ferritic steels in three routes:

I. 9Cr FM steels with $\mathrm{M}_{23} \mathrm{C}_{6}, \mathrm{ZrC}$ and Laves_C14 as strengthening phases;

II. $\mathrm{Fe}_{2} \mathrm{Zr}$-strengthened $\mathrm{Fe}-\mathrm{Cr}-\mathrm{Zr}$ alloys with fine eutectic microstructure formed from liquid;

III. High-Cr $(>12 \mathrm{Cr}$ ) ferritic steels with the strengthening phase being complex Laves phase precipitated from the ferritic matrix during aging.

During the course of alloy development, it was found that $\mathrm{Zr}$ addition greatly reduces the stable temperature regime of austenite and increases the formation temperature of Laves phase, which prevents the martensite formation. Therefore, only a small amount of $\mathrm{Zr}$ has been designed in $9 \mathrm{Cr}$ FM steels, which have exhibited tensile properties comparable to or moderately improved over Grade 92. A thermomechanical treatment (TMT) was applied to the alloy with moderate improvement, which showed refined microstructure, leading to increased hardness. Tensile and creep properties of the TMT-ed alloy will be evaluated. Eutectically formed $\mathrm{Fe}_{2} \mathrm{Zr}$ in $\mathrm{Fe}-\mathrm{Cr}-\mathrm{Zr}$ alloys led to significant improvement in both strength and ductility at elevated temperatures compared to Grade 92 . The Laves phase displayed excellent coarsening resistance during aging at $750^{\circ} \mathrm{C}$ for $1800 \mathrm{~h}$. The aging led to slight improvements in creep life without noticeable reduction in creep strain. However, the room temperature tensile ductility of the alloys was poor. Composition adjustment and appropriate TMTs will be developed to favor dispersive $\mathrm{Fe}_{2} \mathrm{Zr}$ particles in the matrix for superior strength with adequate ductility. The developed high-Cr ferritic steels have shown controllable tensile properties by a TMT that favors the formation of an increased amount of refined precipitates. Due to the high affinity of $\mathrm{Zr}$ to nitrogen and oxygen, it is critical to minimize the impurities during alloy making to have Zr-bearing alloys with superior performance. 
This page intentionally left blank 


\section{BACKGROUND}

Nuclear power currently provides a significant fraction of the United States' non-carbon emitting power generation. In future years, nuclear power must continue to generate a significant portion of the nation's electricity to meet the growing demand, clean energy goals, and ensure energy independence. New reactors will be an essential part of the expansion of nuclear power. However, given limits on new builds imposed by economics and industrial capacity, the extended service of the existing fleet will also be required.

Advanced structural materials with superior performance at elevated temperatures are always desired for nuclear reactors, which can improve reactor economics, safety margins, and design flexibility. They benefit not only new reactors including advanced light water reactors (LWRs) and fast reactors such as sodium-cooled fast reactor (SFR) primarily designed for management of high-level wastes, but also the extension of the existing fleet when component exchange is needed.

Ferritic-martensitic (FM) steels are an important category of structural materials because of their outstanding resistance to radiation-induced void swelling (e.g., $\sim 1$ vol.\% per 100 displacement-peratom (dpa) in F/M steels versus per $10 \mathrm{dpa}$ in austenitic stainless steels at temperatures above $300^{\circ} \mathrm{C}$ [1]), high thermal conductivity, and low thermal expansion coefficients compared to austenitic stainless steels [2]. The body-centered cubic (bcc) structure of ferrite provides the inherent resistance to void swelling compared to face-centered cubic (fcc) austenitic alloys [3]. The formation of martensite and followed tempering treatment introduced a large amount of lath boundaries and dislocations into the ferrite matrix, leading to refined precipitates, increased strength, and decent fracture toughness [4]. However, the dislocations and lath boundaries are not stable at elevated temperatures, resulting in softening due to the impaired pinning effect induced by the instability of precipitates $[4,5]$.

Zirconium (Zr) has shown many benefits to Fe-base alloys, such as introduced ultrafine new phases, improved coarsening resistance of $\mathrm{Zr}$-bearing phases [6], and reduced radiation-induced segregation (RIS) [7,8]. Thus, it is expected that $\mathrm{Zr}$ has a beneficial role in improving high-temperature performance. This project is to develop $\mathrm{Zr}$-bearing ferritic alloys guided by computational thermodynamics.

In contrast to traditional experimental trial-error method, computational thermodynamics, a scientific approach to systematically study the relationship between thermodynamic properties and phase stability, provides effective and economic practices for alloy development. The primary microstructures of new alloys can be simulated on a desktop computer within a short period of time, which guide the design of new alloys for experimental verification and performance examination.

This report describes the progress of on the mechanical testing and thermal aging of Zr-bearing ferritic steels. It is organized as the following: 1) Developing thermodynamic database of the Fe-CCr-Mo-N-Nb-Ti-W-Zr system 2) Designing alloy compositions and thermal treatments with the aid of computational thermodynamics, and 3 ) Evaluating the microstructural and mechanical properties of designed alloys. 
This page intentionally left blank 


\section{THERMODYNAMIC MODELING OF THE FE-C-CR-MO-NB-TI-W-ZR SYSTEM}

\subsection{TECHNICAL APPROACH}

Thermodynamic models of phases in the Fe-C-Cr-Mo-Nb-Ti-W-Zr system were identified as important components of computational thermodynamics for the development of Zr-bearing ferritic steels. The CALPHAD (CALculation of PHAse Diagram) approach [9] is used to develop thermodynamic models of phases in this multicomponent system. The essence of this approach is to develop self-consistent thermodynamic models of phases which cannot only describe thermodynamic properties but also phase equilibria of materials.

The most important component of computational thermodynamics is to develop thermodynamic database that is a compilation of Gibbs Energy functions of phases in a system. For each Gibbs energy function, there are two components, thermodynamic models and model parameters. The most frequently used models are solution, compound energy formalism, and line compound [10]. The model selection is based on the crystal structures, defect types and ordering information of phases. Model parameters are optimized based on experimental data such as phase boundary and thermodynamic property measurements such as activity and enthalpy of formation. Successful thermodynamic modeling requires simultaneously satisfying different properties of phases using one set of Gibbs energy functions. For multicomponent systems where the experimental information is often lack, the advantage of this approach is that the Gibbs energies of multicomponent phases can be derived from its constituent lower order systems through different geometric rules such as RedlichKister expansions [11]. Based on the obtained Gibbs energies, phase property such as fraction, composition, solidus, liquidus at different temperatures and alloy compositions in an unknown system can be calculated by numerically finding the lowest energy minimum of the system. The software used in this work for computational thermodynamic calculation is Pandat [12] and Thermocalc [13]. The modeling approach is schematically shown in Fig. 1 in next page. 


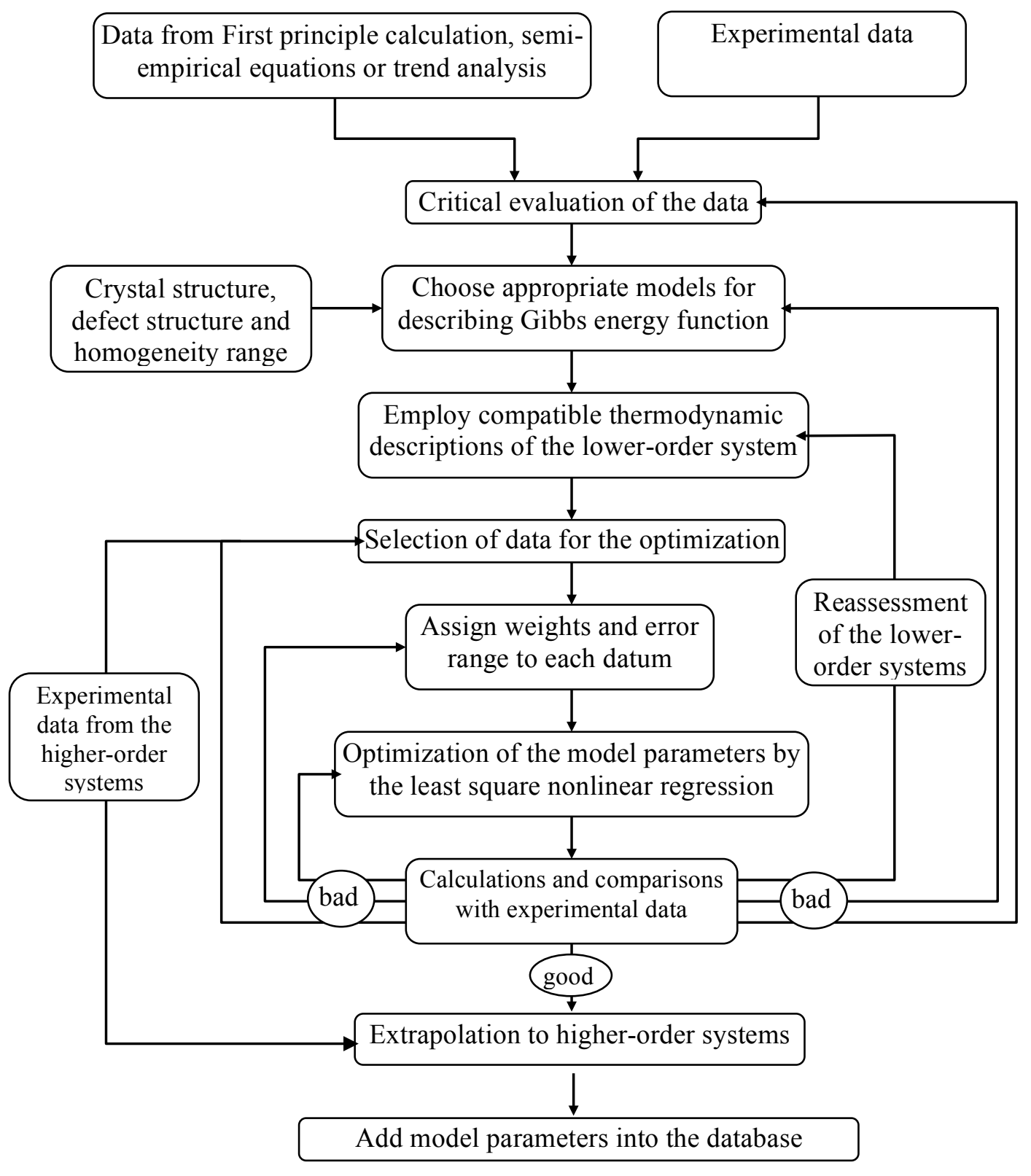

Fig. 1. Flowing chart of developing a thermodynamic description of a multicomponent system.

\subsection{THERMODYNAMIC MODELING OF THE FE-ZR BINARY SYSTEM}

Based on the CALPHAD approach as outlined in Fig. 1, thermodynamic models of phases in constituent of binary and ternary systems of the Fe-C-Cr-Mo-Nb-Ti-W-Zr system need to be developed first. This section uses the Fe-Zr binary as an example to briefly demonstrate the development of thermodynamic models. Details about thermodynamic modeling of this system can be found in the recent publication of "Thermodynamic modeling and experimental study of Fe-Cr- $\mathrm{Zr}$ system" [14] that is generated from this work.

Firstly, the relevant phases in the Fe-Zr system have been reviewed. Based on their crystallography data and homogeneity ranges, thermodynamic models such as Substitutional Solution (SS) model and 
Compound Energy Formalism (CEF) were assigned to each phase, as shown in Table 1. The Gibbs energy of each phase is then described by a mathematic formula according to selected thermodynamic models [10]. These equations contain model parameters to be optimized based on experimental data.

Table 1. Phase name, crystallography, and thermodynamic models

\begin{tabular}{|c|c|c|c|}
\hline Phase name & Pearson symbol & Space group & Thermodynamic model ${ }^{a}$ \\
\hline Liquid & & & $\mathrm{SS}-(\mathrm{Fe}, \mathrm{Zr})_{1}$ \\
\hline$\alpha(Z r)$ & $h P 2$ & $\mathrm{PG}_{3} / m m c$ & $\mathrm{CEF}-(\mathrm{Fe}, \mathrm{Zr})_{1}(\mathrm{Va})_{0.5}$ \\
\hline $\begin{array}{c}\beta(\mathrm{Fe}, \mathrm{Zr}) \\
\delta(\mathrm{Fe})\end{array}$ & $c I 2$ & $\operatorname{Im} \overline{3} m$ & $\mathrm{CEF}-(\mathrm{Fe}, \mathrm{Zr})_{1}(\mathrm{Va})_{3}$ \\
\hline$\gamma(\mathrm{Fe})$ & $c F 4$ & $F m \overline{3} m$ & $\mathrm{CEF}-(\mathbf{F e}, \mathrm{Zr})_{1}(\mathrm{Va})_{1}$ \\
\hline $\begin{array}{c}\mathrm{Fe}_{2} \mathrm{Zr} \mathrm{H}^{b} \\
\left\{\mathrm{Fe}_{2} \mathrm{Zr}-\mathrm{C} 14,\right. \\
\left.\left.\mathrm{Fe}_{2} \mathrm{Zr} \_\mathrm{C} 36\right)\right\}\end{array}$ & $h P 12 / h P 24$ & $\mathrm{PG}_{3} / m m c$ & $\mathrm{CEF}-(\mathbf{F e}, \mathrm{Zr})_{2}(\mathrm{Fe}, \mathbf{Z r})_{1}$ \\
\hline $\begin{array}{c}\mathrm{Fe}_{2} \mathrm{Zr} \mathrm{C}^{\mathrm{c}} \\
\left\{\mathrm{Fe}_{2} \mathrm{Zr}-\mathrm{C} 15\right\}\end{array}$ & $c F 24$ & $F d \overline{3} m$ & $\mathrm{CEF}-(\mathbf{F e}, \mathrm{Zr})_{2}(\mathrm{Fe}, \mathbf{Z r})_{1}$ \\
\hline $\mathrm{FeZr}_{2}$ & $t I 12$ & $\mathrm{I} / \mathrm{mcm}$ & $\mathrm{CEF}-(\mathbf{F e}, \mathrm{Zr})_{1}(\mathrm{Fe}, \mathbf{Z r})_{2}$ \\
\hline $\mathrm{FeZr}_{3}$ & $o C 16$ & Cmcm & $\mathrm{CEF}-(\mathbf{F e}, \mathrm{Zr})_{1}(\mathrm{Fe}, \mathbf{Z r})_{3}$ \\
\hline $\mathrm{Fe}_{23} \mathrm{Zr}_{6}$ & $c F 116$ & $F m \overline{3} m$ & $\mathrm{LC}-\mathrm{Fe}_{23} \mathrm{Zr}_{6}$ \\
\hline $\begin{array}{l}\text { Note: } \\
{ }^{a} \mathrm{SS} \text { denotes } \\
\text { "LC" line compo } \\
\text { the major species } \\
{ }_{b}^{b} \mathrm{Fe}_{2} \mathrm{Zr} \mathrm{H} \text { de } \\
\quad{ }^{c} \mathrm{Fe}_{2} \mathrm{Zr} \text { _C de }\end{array}$ & $\begin{array}{l}\text { sititutional Solution } \\
\text { The element in bol } \\
\text { he corresponding cr } \\
s \text { the hexagonal for } \\
s \text { the cubic form of }\end{array}$ & $\begin{array}{l}\text { del, "CEF" the } \\
\text { nt in the therm } \\
\text { llographic site } \\
\text { f Laves phase } \\
\text { es phase C15 }\end{array}$ & $\begin{array}{l}\text { pound Energy Formalism, } \\
\text { amic model means that it is } \\
\text { can be } \mathrm{C} 14 \text { or C } 36 \text {. }\end{array}$ \\
\hline
\end{tabular}

Secondly, detailed experimental data including both phase equilibrium and thermodynamic property have been reviewed. The currently accepted Fe-Zr phase equilibrium data are mainly based on the work by Stain et al. [15]. Thermodynamic property data including measured mixing enthalpy of liquid at $1900 \mathrm{~K}$ are available experimentally [16-19]. Additionally, ab-initio calculated enthalpies of compounds at $0 \mathrm{~K}$ are available from the works of Ohodnicki et al. [20] and Barberis et al. [21].

Thirdly, previous thermodynamic modeling of the Fe-Zr system, if any, has been reviewed and compared with all available experimental data up to date. The Fe-Zr system was modeled by several authors [22-24], but their calculated enthalpies of compounds show large deviations from the ab-initio calculated results [20-21]. Attempts to use the existing Fe-Zr thermodynamic descriptions [22-24] to develop thermodynamic models for the $\mathrm{Fe}-\mathrm{Cr}-\mathrm{Zr}$ system encountered great difficulties. Therefore, a new thermodynamic description of the Fe-Zr system was developed by taking into account both experimental data and ab-initio calculated results. Thermodynamic models and model parameters of phases in the Fe-Zr system were optimized in this work using experimental data in literature including phase equilibria [15], mixing enthalpy of liquid over 1900K [16-19], and the ab-initio calculated enthalpies of formation of compounds [20,21].

Fourthly, the calculated Fe-Zr binary phase diagram is shown in Fig. 2 (next page) as compared with experimental data from Stain et al. [15]. The calculated enthalpy of mixing of liquid is compared to the experimental data in Fig. 3 (next page). 


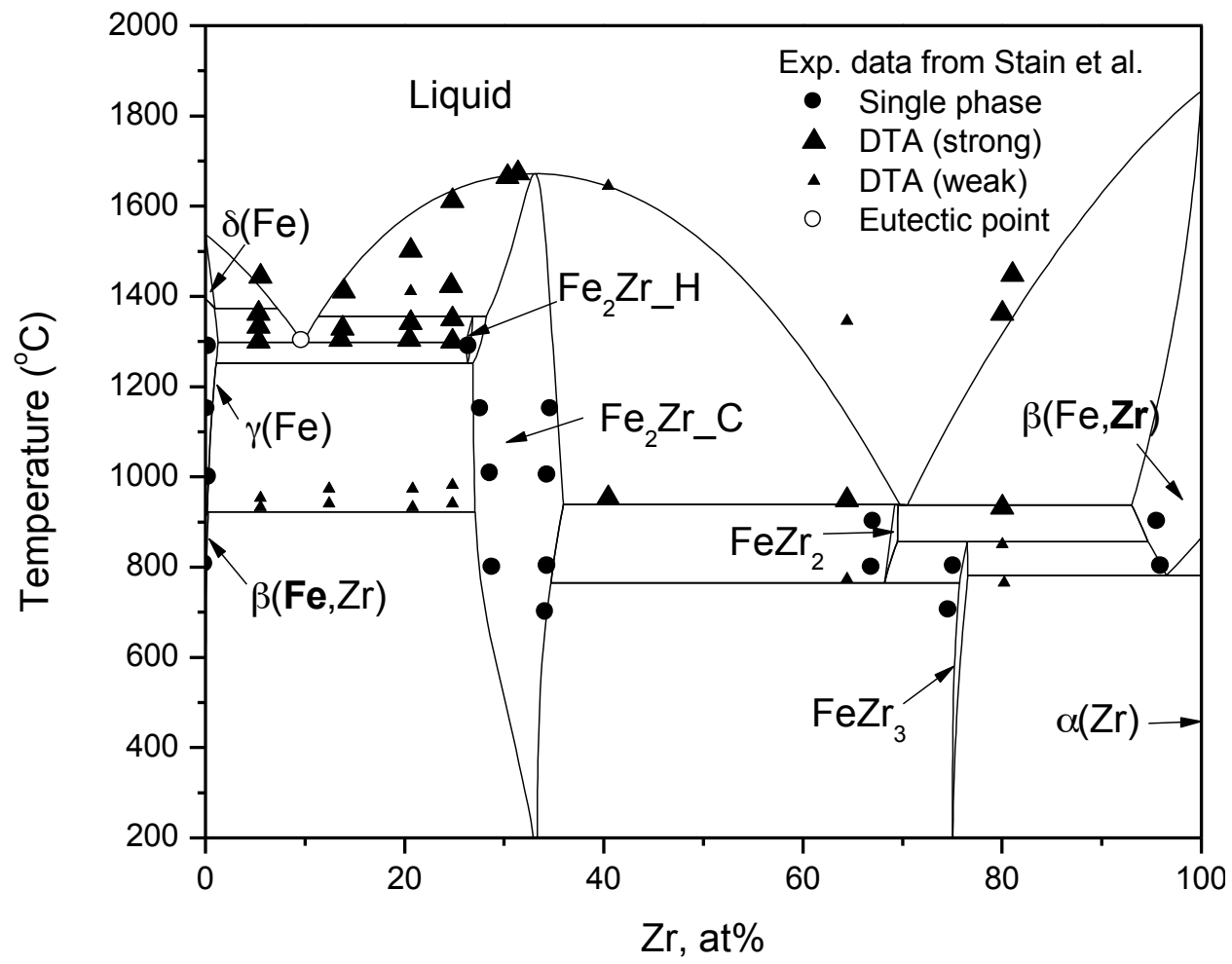

Fig. 2. Calculated Fe-Zr binary phase diagram compared with experimental data from Stain et al. [15]. The element in bold font in $\beta(\mathrm{Fe}, \mathrm{Zr})$ phase denotes the major species.

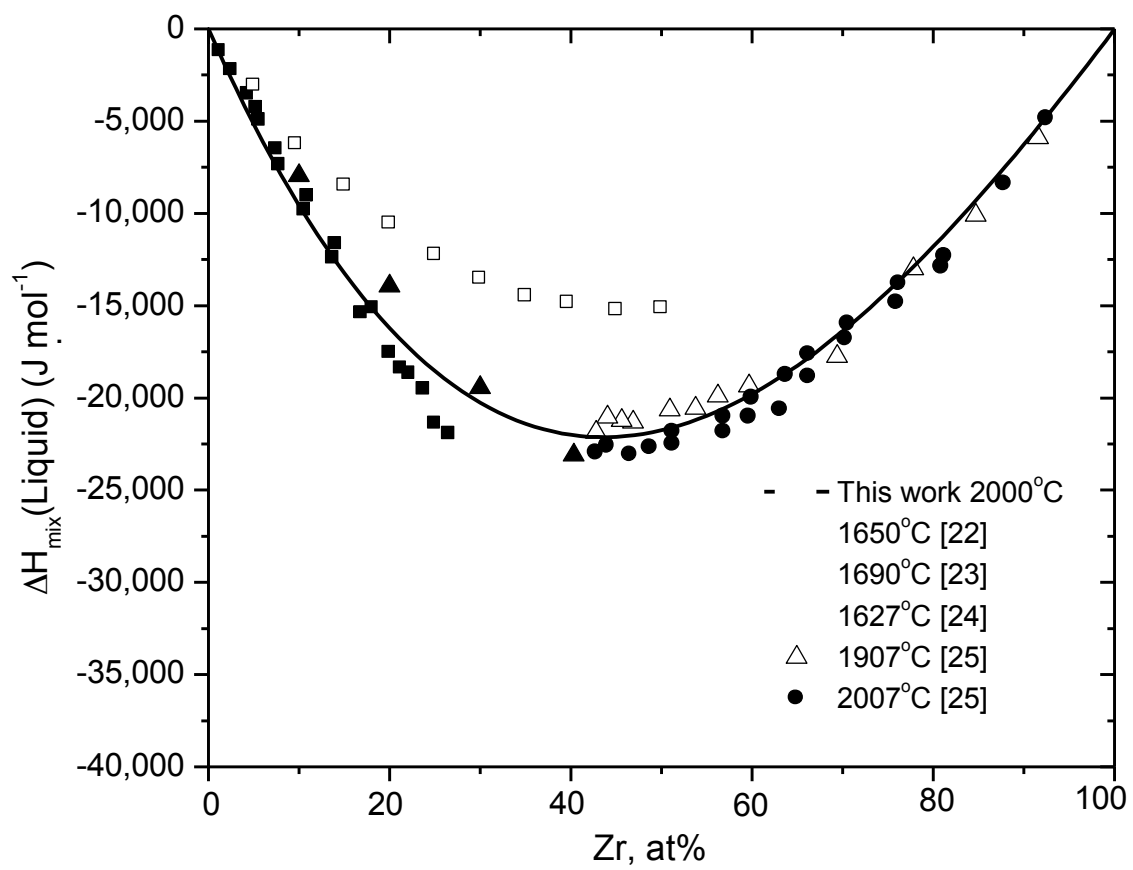

Fig. 3. Calculated enthalpy of mixing of liquid compared with experimental data [16-19]. 
Table 2 lists the comparisons between the calculated invariant reaction and experimental data. Table 3 compares the currently calculated enthalpies of formation of compounds in $\mathrm{Fe}-\mathrm{Zr}$ system at $298 \mathrm{~K}$ to the ab-initio calculated data [20,21], showing better agreement of the current modeling results than the previous Calphad modeling results [16-19]. The good agreements between the calculated results and all available experimental data or ab-initio calculated data validate the reliability of the current thermodynamic modeling. Then, the validated models and parameters are stored into the database for developing thermodynamic description of the multicomponent system.

Table 2. Invariant reactions in the Fe-Zr system

\begin{tabular}{|c|c|c|c|c|c|}
\hline Reaction & Temp. $\left({ }^{\circ} \mathrm{C}\right)$ & \multicolumn{3}{|c|}{ Liquid composition (at\%) } & $\begin{array}{l}\text { References } \\
\text { Comments }\end{array}$ \\
\hline $\mathrm{Fe}-\mathrm{Zr}$ & & \multicolumn{3}{|l|}{$\mathrm{Zr}$} & \\
\hline $\mathrm{L} \leftrightarrow \mathrm{Fe}_{2} \mathrm{Zr} \_\mathrm{C}$ & $\begin{array}{l}1672 \\
1673\end{array}$ & $\begin{array}{l}33.5 \\
\sim 33\end{array}$ & $\begin{array}{l}33.5 \\
\sim 33\end{array}$ & & $\begin{array}{l}\text { This work } \\
\text { Exp. [15] }\end{array}$ \\
\hline$\delta(\mathrm{Fe}) \leftrightarrow \mathrm{L}+\gamma(\mathrm{Fe})$ & $\begin{array}{l}1373 \\
1374 \pm 2\end{array}$ & 1 & 7.2 & 1 & $\begin{array}{l}\text { This work } \\
\text { Exp. [15] }\end{array}$ \\
\hline $\mathrm{L}+\mathrm{Fe}_{2} \mathrm{Zr} \_\mathrm{C} \leftrightarrow \mathrm{Fe}_{2} \mathrm{Zr} \_\mathrm{H}$ & $\begin{array}{l}1355 \\
1345 \pm 10\end{array}$ & 11.3 & 28.2 & 26.8 & $\begin{array}{l}\text { This work } \\
\text { Exp. [15] }\end{array}$ \\
\hline $\mathrm{L} \leftrightarrow \gamma(\mathrm{Fe})+\mathrm{Fe}_{2} \mathrm{Zr} \_\mathrm{H}$ & $\begin{array}{l}1299 \\
1305 \pm 2\end{array}$ & $\begin{array}{l}9.8 \\
9.8 \pm 0.4\end{array}$ & 1.3 & $\begin{array}{l}26.1 \\
26.5 \pm 0.5\end{array}$ & $\begin{array}{l}\text { This work } \\
\text { Exp. [15] }\end{array}$ \\
\hline $\mathrm{Fe}_{2} \mathrm{Zr} \_\mathrm{H} \leftrightarrow \mathrm{Fe}_{2} \mathrm{Zr}-\mathrm{C}+\gamma(\mathrm{Fe})$ & $\begin{array}{l}1252 \\
1240 \pm 10\end{array}$ & 26.3 & 26.8 & 1.1 & $\begin{array}{l}\text { This work } \\
\text { Exp. [15] }\end{array}$ \\
\hline $\mathrm{Fe}_{2} \mathrm{Zr} \_\mathrm{C}+\gamma(\mathrm{Fe}) \leftrightarrow \beta(\mathrm{Fe}, \mathrm{Zr})$ & $\begin{array}{l}923 \\
935 \pm 10\end{array}$ & $\begin{array}{l}27.1 \\
28.6 \pm 0.5\end{array}$ & 0.2 & 0.3 & $\begin{array}{l}\text { This work } \\
\text { Exp. [15] }\end{array}$ \\
\hline$\beta(\mathrm{Fe}, \mathrm{Zr}) \leftrightarrow \mathrm{FeZr}_{3}+\alpha(\mathrm{Zr})$ & $\begin{array}{l}782 \\
775 \pm 4\end{array}$ & $\begin{array}{l}96.5 \\
96 \pm 0.5\end{array}$ & $\begin{array}{l}76.5 \\
75.5 \pm 0.5\end{array}$ & 100 & $\begin{array}{l}\text { This work } \\
\text { Exp. [15] }\end{array}$ \\
\hline $\mathrm{L} \leftrightarrow \mathrm{FeZr}_{2}+\beta(\mathrm{Fe}, \mathrm{Zr})$ & $\begin{array}{l}938 \\
928 \pm 2\end{array}$ & $\begin{array}{l}71 \\
76 \pm 1\end{array}$ & $\begin{array}{l}69.5 \\
67 \pm 0.5\end{array}$ & $\begin{array}{l}93 \\
95.8 \pm 0.5\end{array}$ & $\begin{array}{l}\text { This work } \\
\text { Exp. [15] }\end{array}$ \\
\hline $\mathrm{L}+\mathrm{Fe}_{2} \mathrm{Zr} \_\mathrm{C} \leftrightarrow \mathrm{FeZr}_{2}$ & $\begin{array}{l}939 \\
951 \pm 2\end{array}$ & $\begin{array}{l}70 \\
73 \pm 1\end{array}$ & $\begin{array}{l}35.9 \\
34.4 \pm 0.2\end{array}$ & $\begin{array}{l}69.2 \\
66.7 \pm 0.5\end{array}$ & $\begin{array}{l}\text { This work } \\
\text { Exp. [15] }\end{array}$ \\
\hline $\mathrm{FeZr}_{2}+\beta(\mathrm{Fe}, \mathrm{Zr}) \leftrightarrow \mathrm{FeZr}_{3}$ & $\begin{array}{l}856 \\
851 \pm 2\end{array}$ & $\begin{array}{l}69.5 \\
67 \pm 0.5\end{array}$ & $\begin{array}{l}94.6 \\
95.9 \pm 0.5\end{array}$ & $\begin{array}{l}76.5 \\
75 \pm 0.5\end{array}$ & $\begin{array}{l}\text { This work } \\
\text { Exp. [15] }\end{array}$ \\
\hline $\mathrm{FeZr}_{2} \leftrightarrow \mathrm{Fe}_{2} \mathrm{Zr} \mathrm{C}_{-} \mathrm{C}+\mathrm{FeZr}_{3}$ & $\begin{array}{l}766 \\
780 \pm 2\end{array}$ & $\begin{array}{l}68.2 \\
66.7 \pm 0.5\end{array}$ & $\begin{array}{l}34.6 \\
34.4 \pm 0.2\end{array}$ & $\begin{array}{l}75.7 \\
74.5 \pm 0.5\end{array}$ & $\begin{array}{l}\text { This work } \\
\text { Exp. [15] }\end{array}$ \\
\hline
\end{tabular}

Table 3. Calculated enthalpies of formation of compounds in the $\mathrm{Fe}-\mathrm{Zr}$ system compared with literature data ("C": Calphad modeling; "a" ab-initio calculation)

\begin{tabular}{ccccc}
\hline $\mathbf{F e}_{23} \mathbf{Z r}_{\mathbf{6}}$ & $\mathbf{F e}_{2} \mathbf{Z r} \mathbf{C}$ & $\mathbf{F e Z r}_{\mathbf{2}}$ & $\mathbf{F e Z r}_{\mathbf{3}}$ & Reference \\
\hline-16648 & -28954 & -15434 & -14463 & This work (C) \\
-23288 & -24638 & -17616 & 13158 & Servant (C) [22] \\
-16700 & -25380 & -20434 & -16118 & Jiang (C) [23] \\
& -30446 & -12812 & -20020 & Guo (C) [24] \\
-16650 & -28070 & -16070 & -14340 & Ohodnicki (a) [20] \\
& -28560 & -15714 & -13810 & Barberis(a) [21] \\
\hline
\end{tabular}




\subsection{THE CURRENT STATUS OF THE FE-C-CR-MO-NB-TI-W-ZR SYSTEM}

A thermodynamic property database of the Fe-C-Cr-Mo-Nb-Ti-W-Zr system has been developed in this study. This database is built upon the thermodynamic database OCTANT (ORNL Computational Thermodynamics Applied to Nuclear Technology) [25] that consists of elements of Fe, C, Cr, Mn, $\mathrm{Mo}, \mathrm{N}, \mathrm{Nb}, \mathrm{Ni}, \mathrm{Si}$, and Ti. Although the OCTANT is primarily developed for understanding the complex precipitates in austenitic steels, it contains common elements that are also important to ferritic steels. By comparing the alloying elements needed for Zr-bearing ferritic steels with those existing in the OCTANT, $\mathrm{Zr}$ and $\mathrm{W}$ are two new elements. Therefore, the thermodynamic modeling effort in this work is to incorporate thermodynamic models of phases in $\mathrm{Zr}$ - and $\mathrm{W}$ - containing binary and ternary systems into the OCTANT database. The modeling of $\mathrm{Zr}$ - and $\mathrm{W}$ - containing binary and ternary systems follows the same approach as the Fe-Zr system as described in Section 2.2.

To better summarize the current thermodynamic modeling status of the Fe-C-Cr-Mo-Nb-Ti-W-Zr system and understand the application limit, all relevant information is listed in Tables 4-6. There are a total of 28 constituent binaries and 56 ternaries in the Fe-C-Cr-Mo-Nb-Ti-W-Zr system. All binaries have been thermodynamically modeled in literature. The published model parameters have been evaluated, made to be self-consistent, and compiled into the OCTANT database. The status of the modeled binaries is listed in Table 4. The list of references is available upon request. The systems in bold and italic font are results from thermodynamic modeling effort in this study.

Table 4. The status of binary systems in the Fe-C-Cr-Mo-Nb-Ti-W-Zr system

\begin{tabular}{|c|c|c|c|c|c|c|c|}
\hline & $\mathrm{C}$ & $\mathrm{Cr}$ & Mo & Nb & $\mathbf{T i}$ & $\mathbf{W}$ & $\mathbf{Z r}$ \\
\hline $\mathrm{Fe}$ & $\mathrm{Fe}-\mathrm{C}$ & $\mathrm{Fe}-\mathrm{Cr}$ & $\mathrm{Fe}-\mathrm{Mo}$ & $\mathrm{Fe}-\mathrm{Nb}$ & $\overline{\mathrm{Fe}-\mathrm{Ti}}$ & $F e-W$ & $F e-Z r$ \\
\hline $\mathrm{C}$ & & $\mathrm{C}-\mathrm{Cr}$ & C-Mo & $\mathrm{C}-\mathrm{Nb}$ & C-Ti & $C-W$ & $C-Z r$ \\
\hline $\mathrm{Cr}$ & & & Cr-Mo & $\mathrm{Cr}-\mathrm{Nb}$ & $\mathrm{Cr}-\mathrm{Ti}$ & $C r-W$ & $\mathrm{Cr}-\mathrm{Zr}$ \\
\hline Mo & & & & Mo-Nb & Mo-Ti & $M o-W$ & $M o-Z r$ \\
\hline $\mathrm{Nb}$ & & & & & $\mathrm{Nb}-\mathrm{Ti}$ & $N b-W$ & $N b-Z r$ \\
\hline $\mathrm{Ti}$ & & & & & & $T i-W$ & $T i-Z r$ \\
\hline W & & & & & & & $W-Z r$ \\
\hline
\end{tabular}

Out of the 56 ternaries, the Fe-containing systems were critically evaluated. Table 5 lists the status of the Fe-containing ternary systems. The systems in green suggest that their thermodynamic descriptions were available from literature and adopted in the database. For the systems in yellow, their model parameters were optimized in present work based on experimental data, as that was done for the Fe-Cr-Zr system [14]. Even though some ternaries in yellow were thermodynamically modeled in literature, the published parameters cannot be used due to either model incompatibility with other systems or unsatisfactory agreement with experimental data. With thermodynamic descriptions of all binary and Fe-X-Y ternary systems, most of common phases in ferritic steel are covered in the current database. 
Table 5. The status of ternary systems in the Fe-C-Cr-Mo-Nb-Ti-W-Zr system

\begin{tabular}{|c|c|c|c|c|c|c|}
\hline & $\mathrm{Cr}$ & Mo & Nb & $\mathbf{T i}$ & $\mathbf{W}$ & $\mathbf{Z r}$ \\
\hline $\mathrm{Fe}-\mathrm{C}$ & $\mathrm{Fe}-\mathrm{C}-\mathrm{Cr}$ & Fe-C-Mo & $\mathrm{Fe}-\mathrm{C}-\mathrm{Nb}$ & $\mathrm{Fe}-\mathrm{C}-\mathrm{Ti}$ & $\mathrm{Fe}-\mathrm{C}-\mathrm{W}$ & $F e-C-Z r$ \\
\hline $\mathrm{Fe}-\mathrm{Cr}$ & & $\mathrm{Fe}-\mathrm{Cr}-\mathrm{Mo}$ & $\mathrm{Fe}-\mathrm{Cr}-\mathrm{Nb}$ & $\mathrm{Fe}-\mathrm{Cr}-\mathrm{Ti}$ & $\mathrm{Fe}-\mathrm{Cr}-\mathrm{W}$ & $\mathrm{Fe}-\mathrm{Cr}-\mathrm{Zr}$ \\
\hline Fe-Mo & & & $\mathrm{Fe}-\mathrm{Mo}-\mathrm{Nb}$ & Fe-Mo-Ti & $F e-M o-W$ & $F e-M o-Z r$ \\
\hline $\mathrm{Fe}-\mathrm{Nb}$ & & & & $\mathrm{Fe}-\mathrm{Nb}-\mathrm{Ti}$ & $F e-N b-W$ & $F e-N b-Z r$ \\
\hline Fe-Ti & & & & & $F e-T i-W$ & $F e-T i-Z r$ \\
\hline Fe-W & & & & & & $F e-W-Z r$ \\
\hline
\end{tabular}

Because of large chemical affinity between $\mathrm{Zr}$ and $\mathrm{C}, \mathrm{Zr}$ addition significantly affects the $\mathrm{C}$ content in the $\mathrm{Bcc}(\mathrm{Fe})$, and the formation of other metal carbides. Since many types of carbide occur in ternary systems without Fe, it is necessary to model those MC forming systems. Table 6 lists the thermodynamic modeling status of MC forming ternary systems without $\mathrm{Fe}$.

Table 6. The status of MC forming ternary systems (without Fe) in the Fe-C-Cr-Mo-Nb-Ti-W-Zr system

\begin{tabular}{|c|c|c|c|c|c|}
\hline & Mo & $\mathrm{Nb}$ & $\mathbf{T i}$ & $\mathbf{W}$ & $\mathbf{Z r}$ \\
\hline $\mathrm{Cr}-\mathrm{C}$ & Cr-Mo-C & $\mathrm{Cr}-\mathrm{Nb}-\mathrm{C}$ & Cr-Ti-C & $C r-W-C$ & $\mathrm{Cr}-\mathrm{Zr}-\mathrm{C}$ \\
\hline Mo-C & & Mo-Nb-C & Mo-Ti-C & $M o-W-C$ & $M o-Z r-C$ \\
\hline $\mathrm{Nb}-\mathrm{C}$ & & & $\mathrm{Nb}-\mathrm{Ti}-\mathrm{C}$ & $N b-W-C$ & $N b-Z r-C$ \\
\hline Ti-C & & & & $T i-W-C$ & $T i-Z r-C$ \\
\hline W-C & & & & & $W-Z r-C$ \\
\hline
\end{tabular}


This page intentionally left blank 


\section{DESIGN AND FABRICATION OF ZR-BEARING FERRITIC ALLOYS AND MICROSTRUCTURAL CHARACTERIZATION}

\subsection{ALLOY DESIGN}

Using the developed computational thermodynamics tool, Zr-containing steels were explored through three design routes. They are:

I. $\quad 9 \mathrm{Cr}$ FM steels with $\mathrm{M}_{23} \mathrm{C}_{6}, \mathrm{ZrC}$ and Laves_C14 as strengthening phases;

II. $\mathrm{Fe}_{2} \mathrm{Zr}$-strengthened $\mathrm{Fe}-\mathrm{Cr}-\mathrm{Zr}$ alloys with fine eutectic microstructure formed from liquid;

III. High-Cr $(>12 \mathrm{Cr})$ ferritic steels with the strengthening phase being the Laves phase precipitated from ferrite during lower temperature aging.

9Cr FM steels are considered because they have lower delta-ferrite formation tendency, lower alphaprime formation tendency under irradiation, and lower tendency to increase the ductile-brittle transition temperature (DBTT) under irradiation, compared to $12 \mathrm{Cr}$ FM steels. A trace amount of $\mathrm{Zr}$ alloying would introduce $\mathrm{ZrC}$, leading to refined grains, reduced $\mathrm{M}_{23} \mathrm{C}_{6}$, and other potential benefits such as adjustment in Laves phase constituent and improvement in resistance to RIS. The properties generated from this category of alloys will be compared with those of commercial 9Cr FM steels such as Grade 91 and/or Grade 92.

The $\mathrm{Fe}_{2} \mathrm{Zr}$-strengthened $\mathrm{Fe}-\mathrm{Cr}-\mathrm{Zr}$ alloys were designed on one hand to support fundamental thermodynamic database development of Zr-bearing alloys, and on the other hand to explore the effect of $\mathrm{Zr}$-bearing Laves phase on mechanical properties of $\mathrm{Fe}-\mathrm{Cr}-\mathrm{Zr}$ alloys. This category of alloys was designed to form ultra-fine eutectic microstructure from liquid. A substantial amount of $\mathrm{Fe}_{2} \mathrm{Zr}$ exists in the microstructure of this category of alloys.

The high-Cr $(>12 \mathrm{Cr})$ ferritic alloys were designed to form a strengthening Laves phase that precipitates from ferrite matrix through solid-state reaction during lower temperature aging. The Laves phase in this category of alloys has a complex composition of $\mathrm{W}, \mathrm{Nb}, \mathrm{Ti}, \mathrm{Zr}$, etc. This category of alloys is anticipated to have better corrosion resistance than lower $\mathrm{Cr}$ steels and less or practical immunity to stress corrosion cracking (SCC) issues compared to austenitic stainless steels, such as 304 and 316 alloys. Two of the representative commercial alloys in this category of alloys are AISI 439 and AISI 444 that are not used in nuclear applications. The properties of this category of alloys will be compared to those of similar alloys AISI 439/444 as well as Grade 91 and 92 steels.

With the aid of computational thermodynamics, the compositions of designed alloys are listed in Table 7 (next page). Many other alloy compositions that were scoped using the calculations are not included here because their phase components are not desirable according to the knowledge accumulated from alloy development practices and literature reports. 
Table 7. Composition (wt.\%) of designed $\mathrm{Zr}$-bearing ferritic alloys with $\mathrm{Fe}$ as balance

\begin{tabular}{|c|c|c|c|c|c|c|c|c|}
\hline Alloy & $\mathbf{C}$ & $\mathrm{Cr}$ & Mn & $\mathbf{N i}$ & $\mathbf{S i}$ & $\mathbf{W}$ & $\mathbf{Z r}$ & $\mathbf{T i}$ \\
\hline \multicolumn{9}{|c|}{ 9Cr FM steels } \\
\hline $\mathrm{Z} 1$ & 0.1 & 8.7 & 0.4 & 0.15 & 0.15 & 1 & 0.2 & \\
\hline $\mathrm{Z} 2$ & 0.05 & 8.5 & 0.5 & 0.15 & 0.15 & 1 & 0.4 & \\
\hline \multicolumn{9}{|l|}{$\mathrm{T}^{a}{ }^{a}$} \\
\hline \multicolumn{9}{|c|}{$\mathrm{Fe}_{2} \mathrm{Zr}$-strengthened $\mathrm{Fe}-\mathrm{Cr}-\mathrm{Zr}$ alloys } \\
\hline $\mathrm{Z3}$ & & 7.95 & & & & & 14.72 & \\
\hline $\mathrm{Z} 4$ & & 12.45 & & & & & 14.03 & \\
\hline $\mathrm{Z} 5$ & & 8.17 & & & & & 7.96 & \\
\hline \multicolumn{9}{|c|}{ High-Cr ferritic steels } \\
\hline LT1 & 0.0079 & 14.9 & 0.45 & & 0.14 & 2.68 & $<0.01$ & 1.44 \\
\hline LZ1 & 0.0045 & 14.8 & 0.41 & & 0.13 & 4.01 & 0.8 & $<0.01$ \\
\hline LZT1 & 0.0024 & 14.8 & 0.44 & & 0.14 & 2.98 & 0.07 & 1.37 \\
\hline $\mathrm{LNTZ}^{a}$ & & & & & & & & \\
\hline
\end{tabular}

${ }^{a}$ Not disclosed here due to potential proprietary concerns.

\subsection{CALCULATED PHASE COMPONENTS OF DESIGNED ALLOYS}

\subsubsection{Cr FM steels}

The diagrams plotting the calculated mole fraction of phases in the alloys as a function of temperature are shown in Fig. 4(a-e), which were used as a guide for designing alloys Z1, Z2, and T3. These three alloys were designed for Zr-bearing 9Cr FM steels. Similar to conventional FM steels, the full-range diagram of alloy Z1 in Fig. 4(a) shows that the alloy is primarily composed of austenite (i.e., Fcc_a1) at high temperatures with a decent range of austenite temperature window, at which normalization treatment is usually conducted. Ferrite (i.e., Bcc_a2) primarily exists at higher and lower temperatures for delta-ferrite and alpha-ferrite, respectively. Tempering is usually conducted at upper alpha-ferrite temperature regime, e.g., $750-780^{\circ} \mathrm{C}$. Figure $4(\mathrm{~b}-\mathrm{d})$ shows the phases' fraction in alloys $\mathrm{Z} 1, \mathrm{Z} 2$, and T3 with $\mathrm{y}$-axis ranging from 0 to 0.03 . The enlargement of $\mathrm{y}$-axis is to facilitate the reading of phases with small fractions. The plot of P92, using the NIMS MJP heat composition [26], is also shown here in Fig. 4(e) for comparison. The $\mathrm{C} / \mathrm{Zr}$ ratio is 0.5 in $\mathrm{Z} 1$ and 0.125 in $\mathrm{Z2}$. As a result, the $\mathrm{M}_{23} \mathrm{C}_{6}$ in $\mathrm{Z} 2$ is fully suppressed. All $\mathrm{C}$ is combined with $\mathrm{Zr}$ to form $\mathrm{MX}$ carbide. In both $\mathrm{Z} 1$ and $\mathrm{Z} 2$ alloys, the formation of MC carbides initiated from liquid. This can be attributed to the high stability of $\mathrm{ZrC}$. The formation of $\mathrm{MC}$ from liquid may lead to the formation of coarse particles and impair the strengthening effects. In addition, the austenite temperature window is narrower in Z2 than in Z1. The slight adjustment of $\mathrm{Cr}$ (ferrite stabilizer) and $\mathrm{Mn}$ (austenite stabilizer) cannot compensate the decrease of austenite temperature window in alloy $\mathrm{Z} 2$, as a result of the decrease of $\mathrm{C}$ (austenite stabilizer) and increase of $\mathrm{Zr}$ (ferrite stabilizer). T3 is carefully designed to simultaneously satisfy the following requirements: 1) The MC carbide precipitates from solid phase; 2) The amount of $\mathrm{M}_{23} \mathrm{C}_{6}$ is reduced comparing to that in P92; and 3) The Z-phase formation is fully suppressed. 


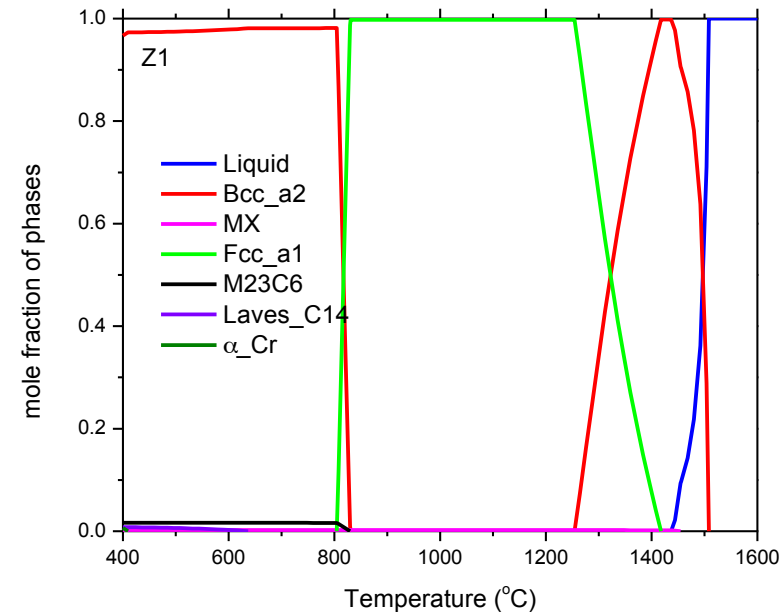

(a) Full scale diagram of $\mathrm{Z1}$

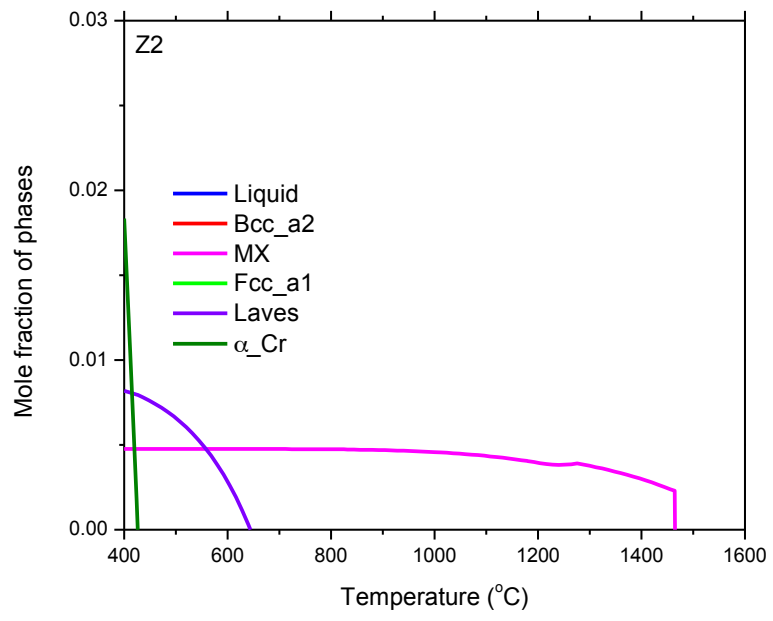

(c) Enlarged diagram of Z2

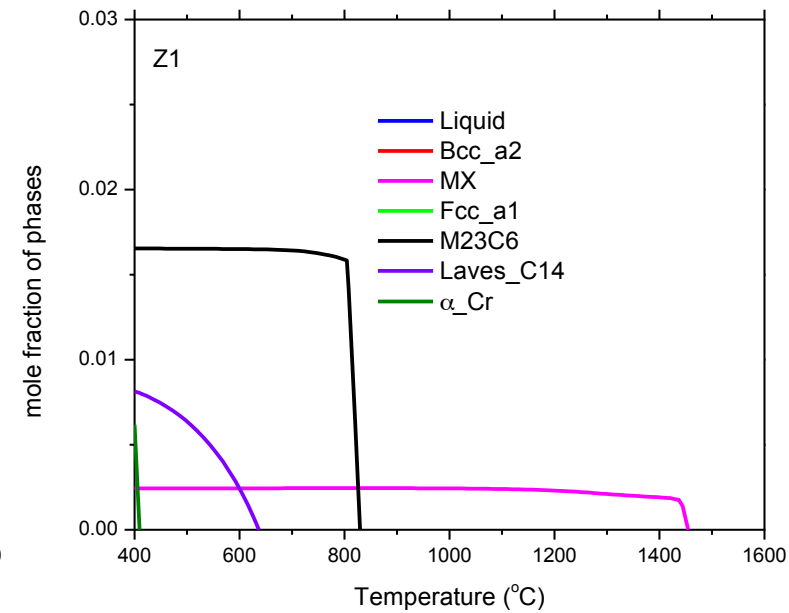

(b) Enlarged diagram of Z1

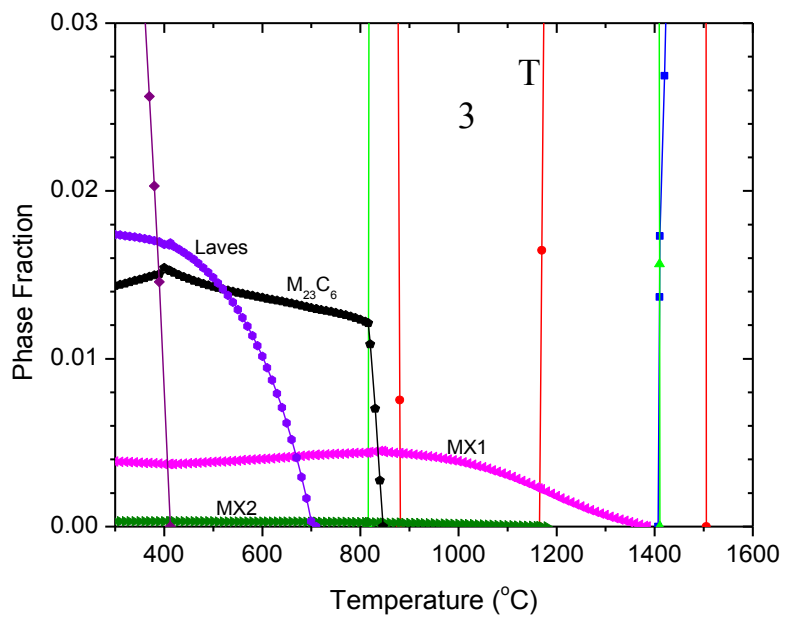

(d) Enlarged diagram of T3

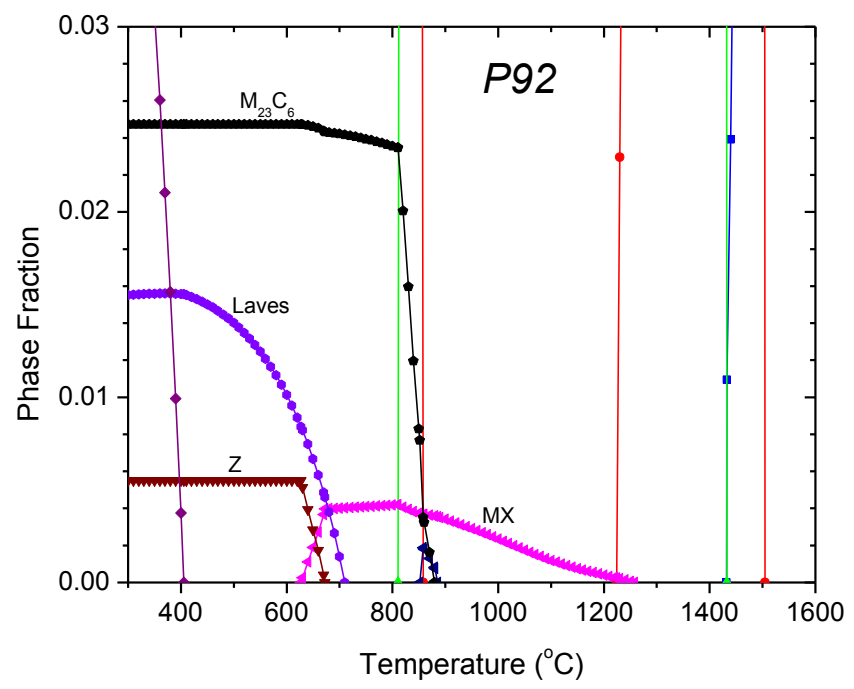

(e) Enlarged diagram of $\mathrm{P} 92$

Fig. 4. Calculated mole fraction of phases as a function of temperature in alloys $\mathrm{Z1}, \mathrm{Z2}$, $\mathrm{T3}$, and $\mathrm{P92}$. 


\subsection{2. $\mathrm{Fe}_{2} \mathrm{Zr}$-strengthened $\mathrm{Fe}-\mathrm{Cr}-\mathrm{Zr}$ alloys}

Alloys Z3, Z4, and Z5 in Table 7 on page 12 are designed as $\mathrm{Fe}_{2} \mathrm{Zr}$-strengthened $\mathrm{Fe}-\mathrm{Cr}$ - $\mathrm{Zr}$ alloys. $\mathrm{The}_{\mathrm{Fe}} \mathrm{Zr}$ phase here has the hexagonal $\mathrm{C} 14$ structure. It should be noted that there is a substantial amount of $\mathrm{Cr}$ within the $\mathrm{Fe}$ sub-lattice of $\mathrm{Fe}_{2} \mathrm{Zr}$ C 14 Laves phase. Figures 5 (a-c) shows the calculated phase fractions vs. temperature in alloys Z3, Z4, and Z5. Alloy Z3 was designed to form ultrafine eutectic microstructure from liquid. The composition of the $Z 3$ is right on the eutectic valley of $\mathrm{Bcc}(\mathrm{Fe})+\mathrm{Fe}_{2} \mathrm{Zr} C \mathrm{C} 14$. Alloy $\mathrm{Z} 4$ has a similar amount of $\mathrm{Zr}$ as alloy $\mathrm{Z3}$ and is also located on the eutectic valley of $\mathrm{Bcc}(\mathrm{Fe})+\mathrm{Fe}_{2} \mathrm{Zr} \_\mathrm{C} 14$. The $\mathrm{Cr}$ content in Bcc_a2 and $\mathrm{Fe}_{2} \mathrm{Zr}$ C 14 in alloy $\mathrm{Z} 4$ is higher than that in alloy Z3. The ratio of the fraction of Bcc a 2 to $\mathrm{Fe}_{2} \mathrm{Zr} \mathrm{C}_{-} \mathrm{C} 14$ is about 2 in alloys Z3 and $Z 4$. By comparing the mechanical properties between alloys $Z 3$ and $\bar{Z} 4$, the effect of $C r$ content can be investigated. Alloy $\mathrm{Z} 5$ has a similar amount of $\mathrm{Cr}$ as $\mathrm{Z3}$, but with a reduced $\mathrm{Zr}$ content. This alloy is located in the primary phase region of $\mathrm{Bcc} \_$a2. The reduced $\mathrm{Zr}$ leads to a larger volume fraction $\mathrm{Bcc}(\mathrm{Fe})$ in the microstructure. The ratio of the fraction of $\mathrm{Bcc} \_\mathrm{a} 2$ to $\mathrm{Fe}_{2} \mathrm{Zr} \mathrm{C} 14$ is about 4 in alloy Z5. By comparing alloys Z3 to Z5, the effect of $\mathrm{Zr}$ on the mechanical properties of $\mathrm{Fe}-\mathrm{Cr}-\mathrm{Zr}$ alloys can be studied. The $\mathrm{Fe}_{2} \mathrm{Zr}$ Laves phase is predicted to have a transformation from $\mathrm{C} 14$ type (hexagonal crystal structure) to C15 type (cubic crystal structure) at temperatures slightly above $400^{\circ} \mathrm{C}$. However, due to slow kinetics at this temperature, it is anticipated that this transformation cannot happen during the present processing and heat treatment conditions. The small austenite temperature window existing in alloy Z5 had not been used for microstructural control. This set of alloys was designed to study the $\mathrm{Cr}$ and $\mathrm{Zr}$ effects on mechanical properties of $\mathrm{Fe}_{2} \mathrm{Zr}$-strengthened $\mathrm{Fe}$ Cr-Zr alloys.

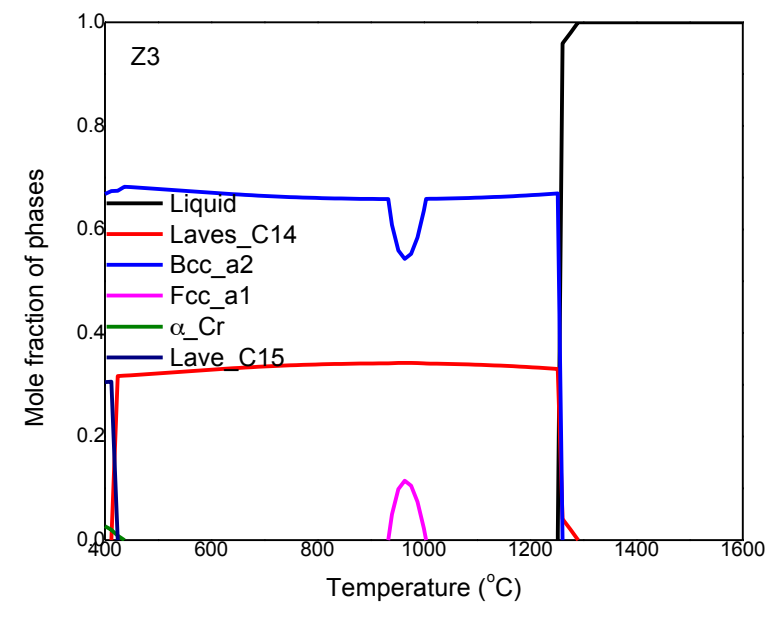

(a) Z3

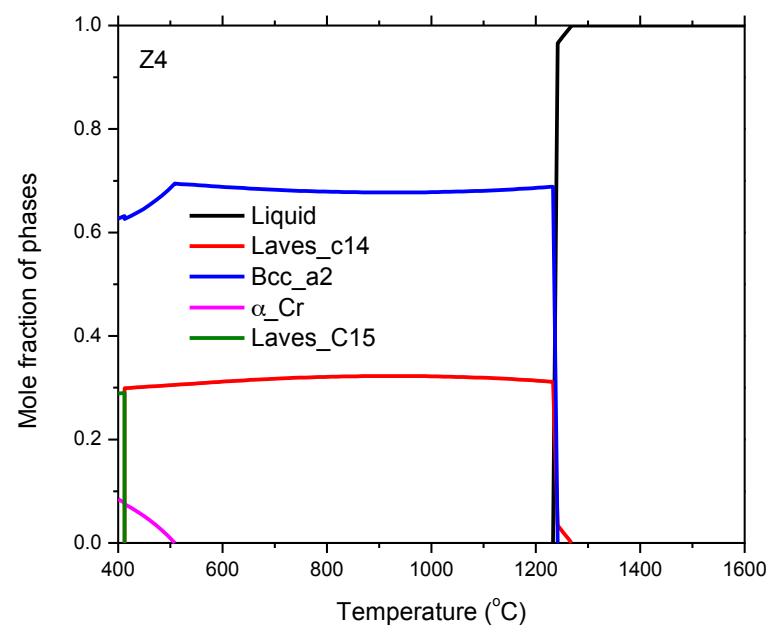

(b) Z4 


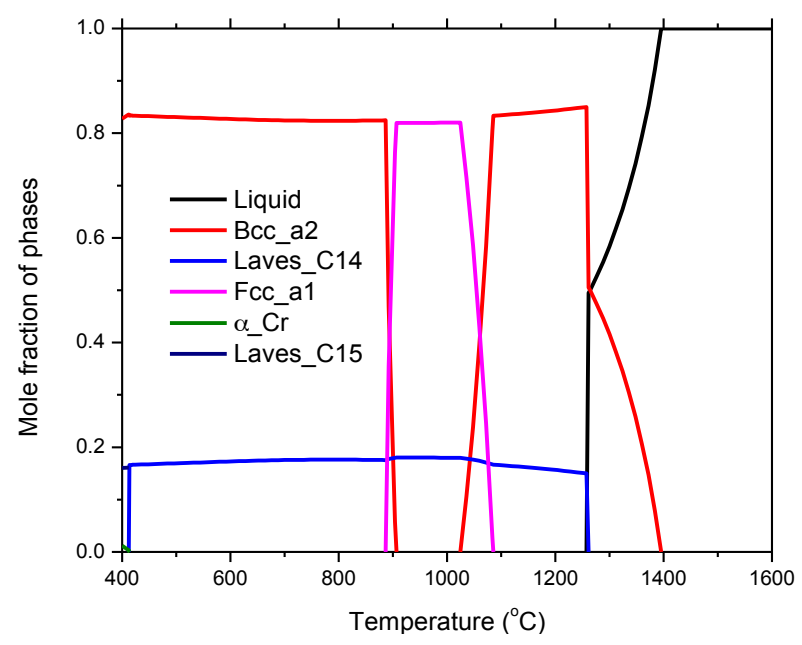

(c) Z5

Fig. 5. Calculated mole fraction of phases as a function of temperature in alloys $\mathrm{Z3}, \mathrm{Z4}$ and $\mathrm{Z5}$.

\subsubsection{High-Cr ferritic alloys}

The calculated fractions of phases vs. temperature in alloys LT1, LZ1, LTZ1, and LNTZ are shown in Figs. 6(a-e). These four alloys were designed for Zr-bearing high-Cr ferritic steels. The full-range diagram of alloy LT1 in Fig. 6(a) shows that the alloy is primarily composed of ferrite (Bcc_a2) and Laves phases. Figures 6(b-e) show the phases' fraction in alloys LT1, LZ1, LTZ1, and LNTZ with yaxis ranging from 0 to 0.1 . The enlarged $y$-axis facilitates the reading of phases with small fractions. In alloys LT1, LZ1, and LTZ1, the Laves phase is essentially the only strengthening phase. Alloy LT1 is designed to have Ti, the LZ1 to have Zr, and LTZ1 to have both. A small amount of MC carbide forms in all three alloys. According to the calculated results in Figs. 6(b-d), MC has the highest precipitation temperature in alloy LZ1. In addition, $\mathrm{Zr}$ addition also increases the precipitation temperature of Laves phase. To obtain the similar precipitation temperature of Laves phase as in alloys LT1 and LTZ1, the amount of other Laves-forming elements in alloy LZ1 such as $\mathrm{W}$ needs to be reduced, which leads to a reduced fraction of Laves phase.

The subsequent microstructural analysis and mechanical tests suggested that formation kinetics of Laves phase is very slow, but once it formed, its coarsening kinetics is fast. Therefore, the LNTZ alloy is designed. In contrast to the negligible amount of MC in alloys LT1, LZ1, and LTZ1, more $\mathrm{MC}$ is designed in alloy LNTZ. The precipitates are anticipated to provide necessary strengthening effect before the formation of Laves phase. The amount of Laves phase is reduced and the chemical complexity of the Laves phase is increased to mitigate the coarsening. 


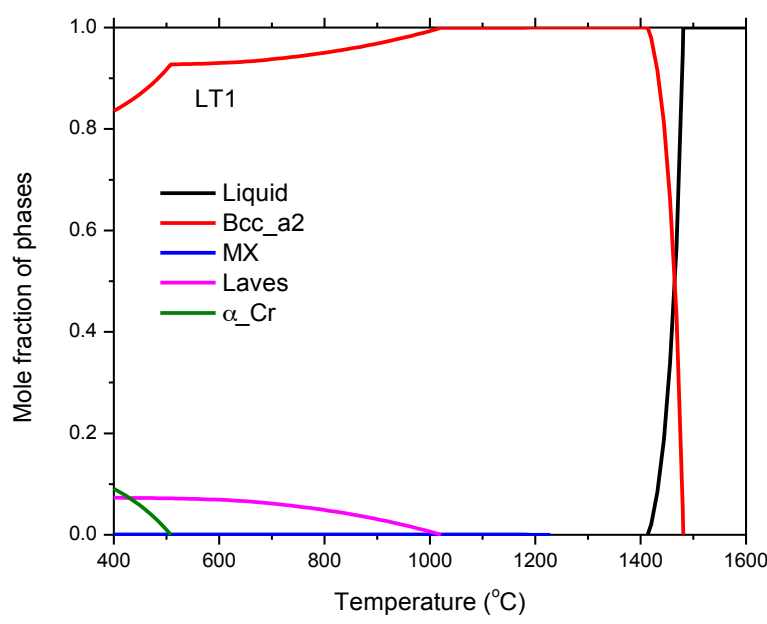

(a) Full-range diagram of LT1

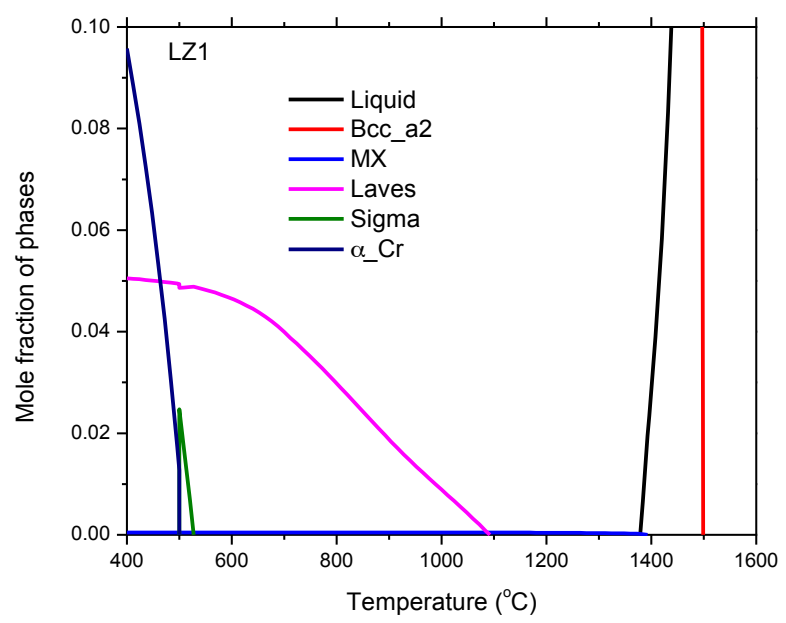

(c) Enlarged diagram of LZ1

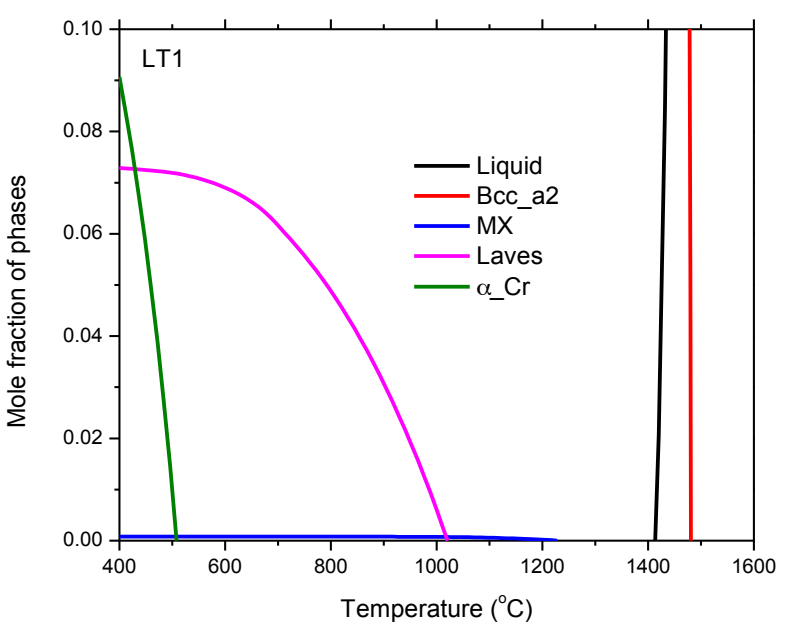

(b) Enlarged diagram of LT1

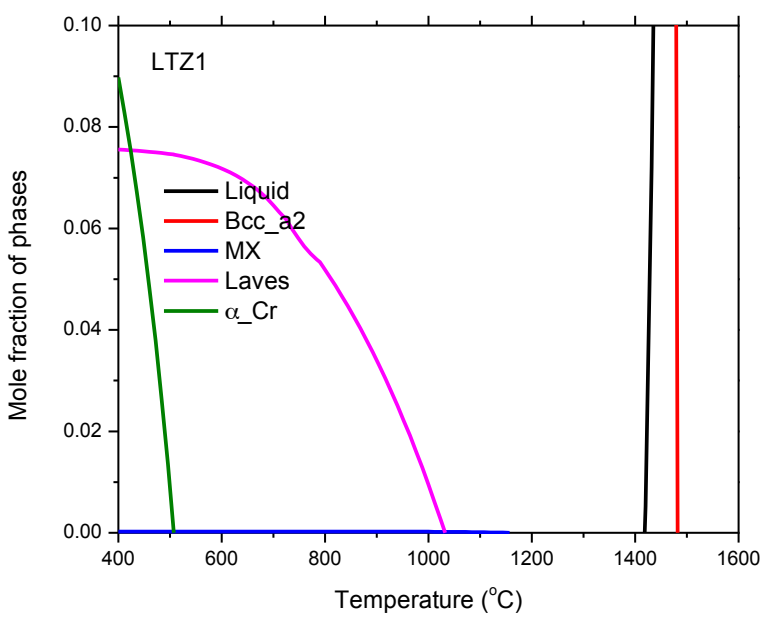

(d) Enlarged diagram of LTZ1

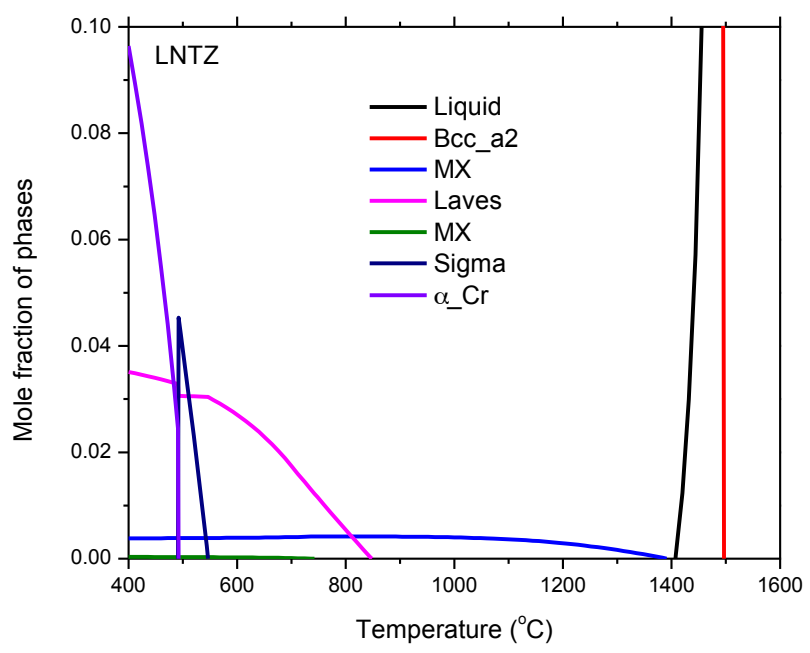

(e) Enlarged diagram of LNTZ

Fig. 6. Calculated temperature-dependent mole fraction of phases in alloys LT1, LZ1, LTZ1, and LNTZ. 


\subsection{ALLOY FABRICATION, THERMAL AND MECHANICAL TREATMENT}

The experimental heats, about $1 \mathrm{lb}$. each, of the designed alloys Z1 through Z5, T3, LT1, LZ1, and LTZ1 have been fabricated using vacuum arc melting and drop casting. Large Zr oxide/nitride inclusions were observed in high-Cr ferritic steels. Chemical analysis on $\mathrm{C}, \mathrm{O}, \mathrm{N}$, and $\mathrm{S}$ was then carried out for LT1, LZ1, and LTZ1 alloys. The results are listed in Table 8. High levels of $\mathrm{O}$ and $\mathrm{N}$ were observed in these alloys, especially for the exceptional amount of $\mathrm{N}$ in alloy LZ1. Therefore, the LNTZ alloy, about 20 lbs., was fabricated at Carpenter Technology through vacuum induction melting. The analyzed $\mathrm{O}$ and $\mathrm{N}$ content in alloy LNTZ indicates that they could be controlled below $\sim 35 \mathrm{ppm}$.

Table 8. Chemical analysis results of $\mathrm{C}, \mathrm{O}, \mathrm{N}$, and $\mathrm{S}(\mathrm{wt} . \%)$ in the high-Cr ferritic steels

\begin{tabular}{ccccc}
\hline Alloy & $\mathbf{C}$ & $\mathbf{O}$ & $\mathbf{N}$ & $\mathbf{S}$ \\
\hline LT1 & 0.0079 & 0.046 & 0.0051 & 0.0028 \\
LZ1 & 0.0045 & 0.016 & 0.035 & 0.0029 \\
LZT1 & 0.0024 & 0.013 & $<0.001$ & 0.0026 \\
LNTZ $^{a}$ & & & & \\
\hline
\end{tabular}

${ }^{a}$ Not disclosed here due to potential proprietary concerns.

The cast ingots were subjected to the processing described in Table 9. Metallographic samples of the processed alloys were prepared following standard grinding and polishing process.

Table 9. Processing of the designed alloys

\begin{tabular}{ll}
\hline Alloy & Processing \\
\hline Z1 & $1150^{\circ} \mathrm{C} / 30 \mathrm{~min}+$ hot rolling $+1150^{\circ} \mathrm{C} / 30 \mathrm{~min} / \mathrm{FAC}+750^{\circ} \mathrm{C} / 60 \mathrm{~min} / \mathrm{AC}$ \\
Z2, T3 & $1100^{\circ} \mathrm{C} / 30 \mathrm{~min}+$ hot rolling $+1100^{\circ} \mathrm{C} / 30 \mathrm{~min} / \mathrm{FAC}+750^{\circ} \mathrm{C} / 60 \mathrm{~min} / \mathrm{AC}$ \\
$\mathrm{Z} 3, \mathrm{Z} 4, \mathrm{Z} 5$ & $1150^{\circ} \mathrm{C} / 20 \mathrm{~min}+$ hot forging $+1150^{\circ} \mathrm{C} / 10 \mathrm{~min} / \mathrm{AC}$ \\
$\mathrm{LT} 1, \mathrm{LZ} 1$ and $\mathrm{LTZ1}$ & $1150^{\circ} \mathrm{C} / 30 \mathrm{~min}+$ hot rolling $+1000^{\circ} \mathrm{C} / 30 \mathrm{~min} / \mathrm{AC}$ \\
LNTZ & $1200^{\circ} \mathrm{C} / 30 \mathrm{~min}+$ hot forging $+1000^{\circ} \mathrm{C} / 30 \mathrm{~min} / \mathrm{AC}$ \\
\hline Note: $\mathrm{FAC}-$ fan-accelerated air cooling; $\mathrm{AC}-$ air cooling
\end{tabular}

\subsection{MICROSTRUCTURE CHARACTERIZATION}

\subsubsection{Cr F/M steels}

Secondary electron images of alloys Z1 and Z2 are shown in Figs. 7. Similar to traditional FM steels, a large amount of tempered martensitic laths were developed in alloy Z1. In contrast, tempered martensitic laths are much fewer in alloy Z2. The large amount of $\mathrm{ZrC}$ precipitates as suggested in Fig. 4(c), which formed from liquid phase and increased during the normalization or austenization rather than tempering process, may have suppressed the development of martensite during air cooling from austenite. Parts of the two alloys were also subjected to annealing at $1150^{\circ} \mathrm{C} / 30 \mathrm{~min}$ followed by water quench. The accelerated cooling rate favored martensite formation in both alloys. However, the martensite amount in alloy Z2 was still less than that in alloy Z1, which is approximately consistent with the standard normalized and tempered condition as shown in Fig. 7. 

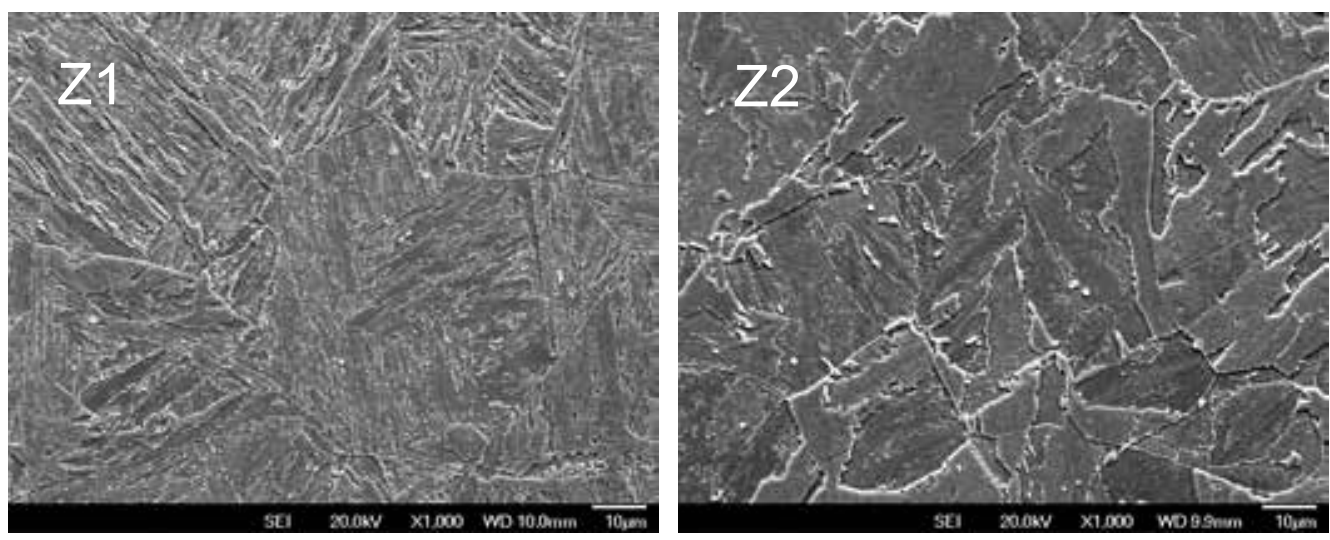

Fig. 7. Secondary electron images of alloys $\mathrm{Z1}$ and $\mathrm{Z2}$ in normalization and tempered condition.

Transmission electron microscopy (TEM) analysis was conducted on the alloy Z1 samples in the water quenched as well as the standard normalized and tempered conditions. The comparison results are shown in Fig. 8. Under the same near [011] two-beam condition of the ferritic matrix, additional diffraction rings exist in the water-quenched sample. The dark-field image using one of the diffraction rings yields a high density of ultrafine particles. The ring pattern could be indexed using face-centered cubic structure with a lattice parameter of $\sim 1.47 \mathrm{a}_{\text {matrix }} .(\mathrm{Cr}, \mathrm{Zr}) \mathrm{C}$ might be the only phase, corresponding to the diffraction rings, within the composition of alloy Z1. In contrast, some additional irregular diffraction spots exist in the tempered sample, which were generated from the large incoherent particles as shown in the bright-field image. This comparison suggests that the $(\mathrm{Cr}, \mathrm{Zr}) \mathrm{C}$ might be a metastable phase under the studied condition.
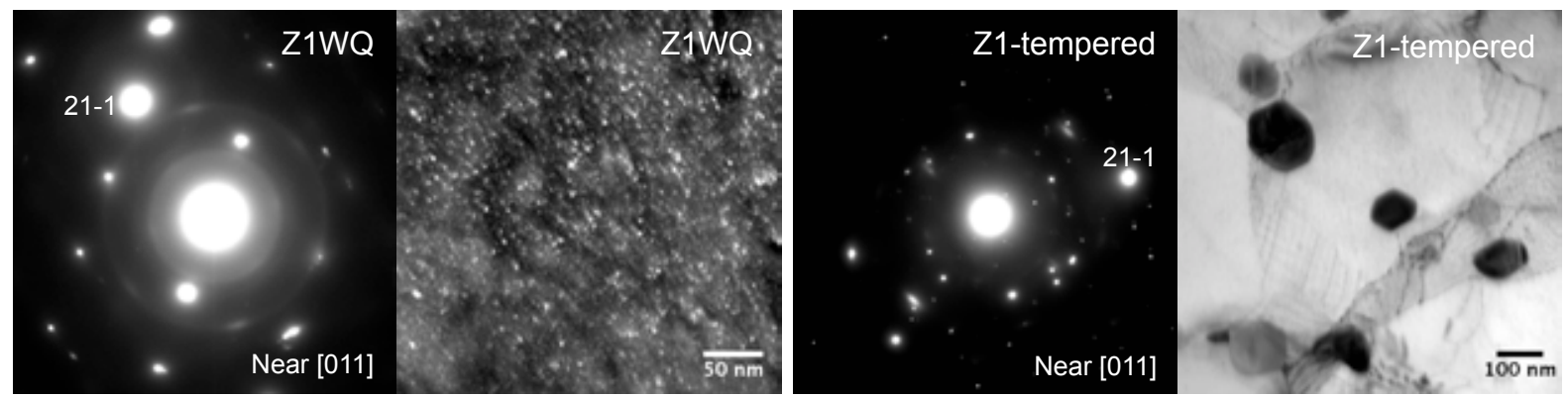

Fig. 8. Bright- and dark-filed images and corresponding diffraction pattern of alloy $\mathrm{Z} 1$ under water quenched and tempered conditions.

The microstructure of the as-fabricated alloy T3 exhibited traditional tempered martensite as shown in Fig. 9. However, the size or width of the laths was somewhat large. Therefore, retreatment to the material by using faster cooling rate, such as water quench, was conducted. The microstructure of the retreated material, as shown in Fig. 9, was much finer than the as-fabricated one, suggesting better strength. 

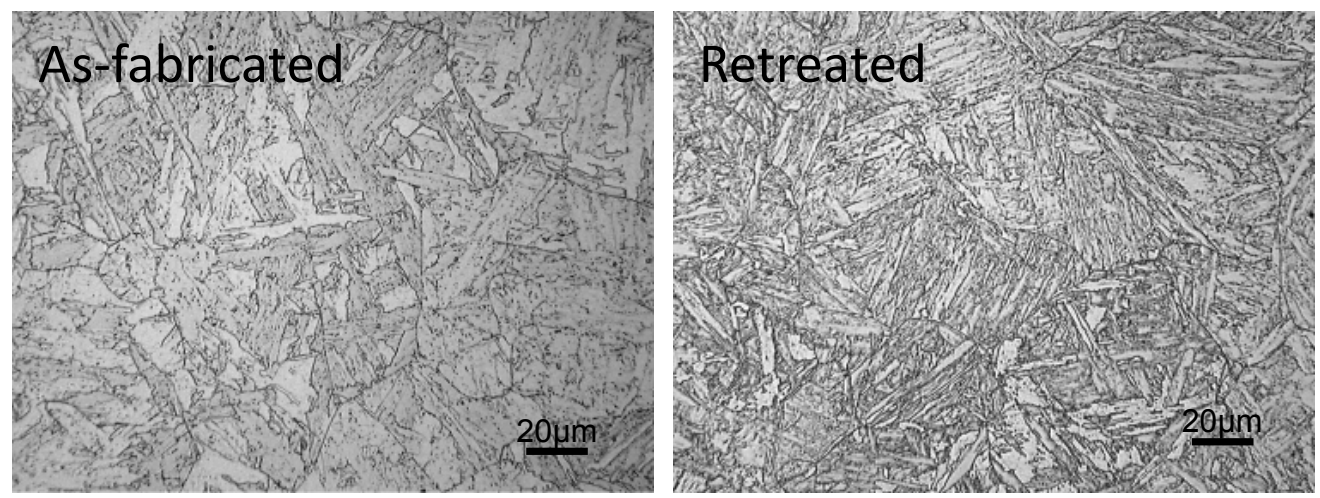

Fig. 9. Optical images of the (a) as-fabricated and (b) retreated alloy $T 3$.

\subsection{2. $\mathrm{Fe}_{2} \mathrm{Zr}$-strengthened $\mathrm{Fe}-\mathrm{Cr}-\mathrm{Zr}$ alloys}

Alloys Z3 through Z5 exhibit distinct microstructures compared to the $9 \mathrm{Cr}$ FM alloys Z1, Z2, and T3. Their backscattered electron (BSE) images are shown in Fig. 10. The phase in high contrast is the $\mathrm{Fe}_{2} \mathrm{Zr}$ phase with a greater elemental mass than the Bcc_a2 phase in low contrast. Alloys Z3 and Z4 have about the same microstructure composed of finely dispersed Laves phase particles and a small amount of large Laves phase $\mathrm{Fe}_{2} \mathrm{Zr}$. The fine $\mathrm{Fe}_{2} \mathrm{Zr}$ phase comes from the eutectic solidification while the large one comes from primary solidification. The small amount of primary $\mathrm{Fe}_{2} \mathrm{Zr}$ phase suggests that both alloys are close to the eutectic valley of Bcc_a2 and $\mathrm{Fe}_{2} \mathrm{Zr}$. In contrast, the microstructure of alloy Z5 is composed of a large fraction of Bcc_a2 primary phase and interdendritic Bcc_a2 $+\mathrm{Fe}_{2} \mathrm{Zr}$ two-phase mixture. This alloy is well located in the Bcc_a2 primary phase region. The observed microstructures in alloys Z3, Z4, and Z5 are consistent with the calculated results in Fig. 5. The hot forging did not effectively break the network formed during solidification.

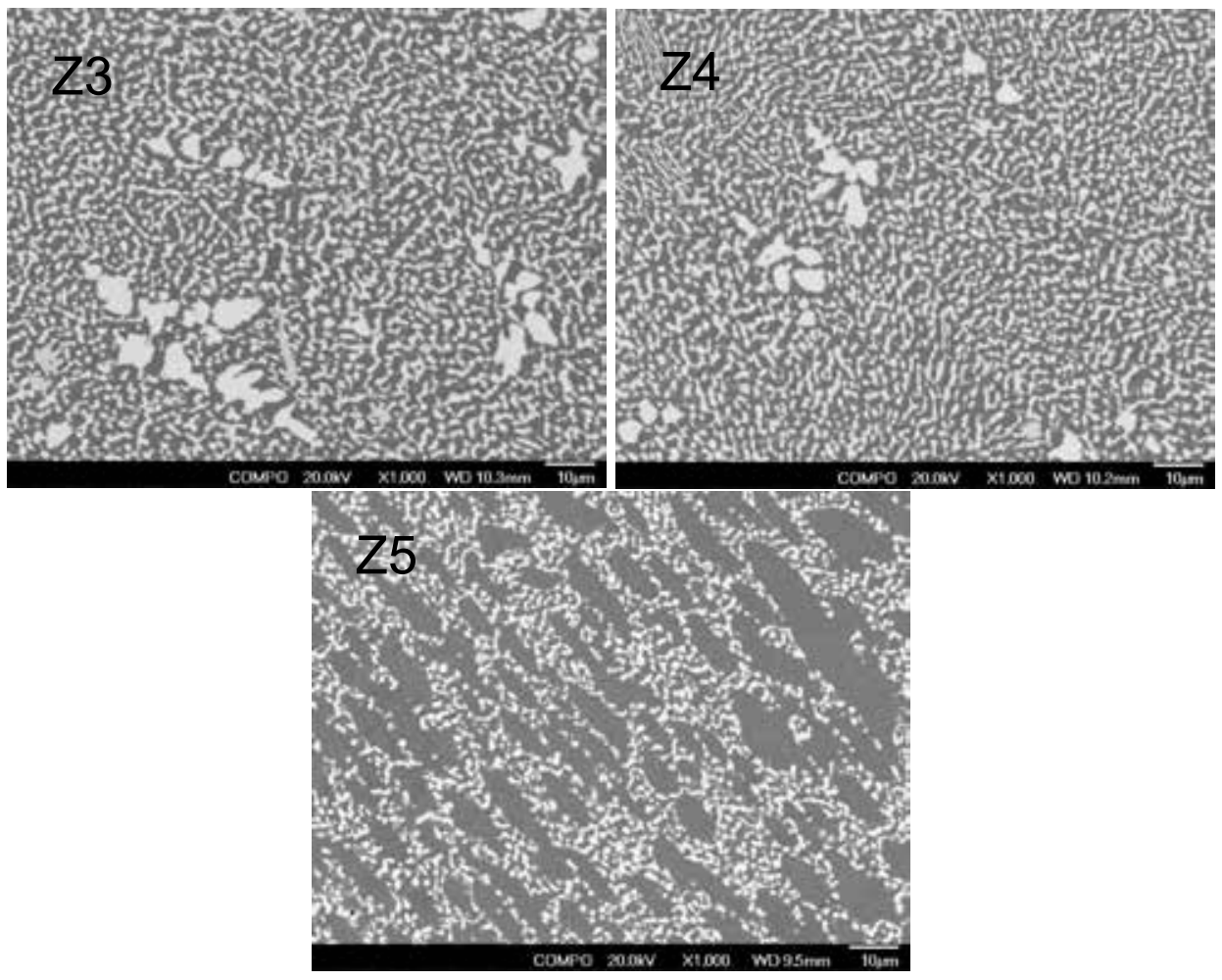

Fig. 10. Backscattered electron images of $\mathrm{Z3}, \mathrm{Z4}$ and $\mathrm{Z5}$ in hot-forged condition. 
To examine how stable such two-phase mixture, alloys Z3, Z4, and Z5 were also subjected to isothermal aging at $750^{\circ} \mathrm{C}$ for $1800 \mathrm{~h}$. The optical images before and after annealing are shown in Fig. 11. The aging did not result in significant changes to the microstructures of the alloys. One noticed change was observed in the aged alloy Z4 that shows Laves phase randomly dispersed in the matrix without the minor preferential orientations of Laves phase in the as-received or as-fabricated condition. Coarsening of the Laves phase was not observed in the aged alloys.
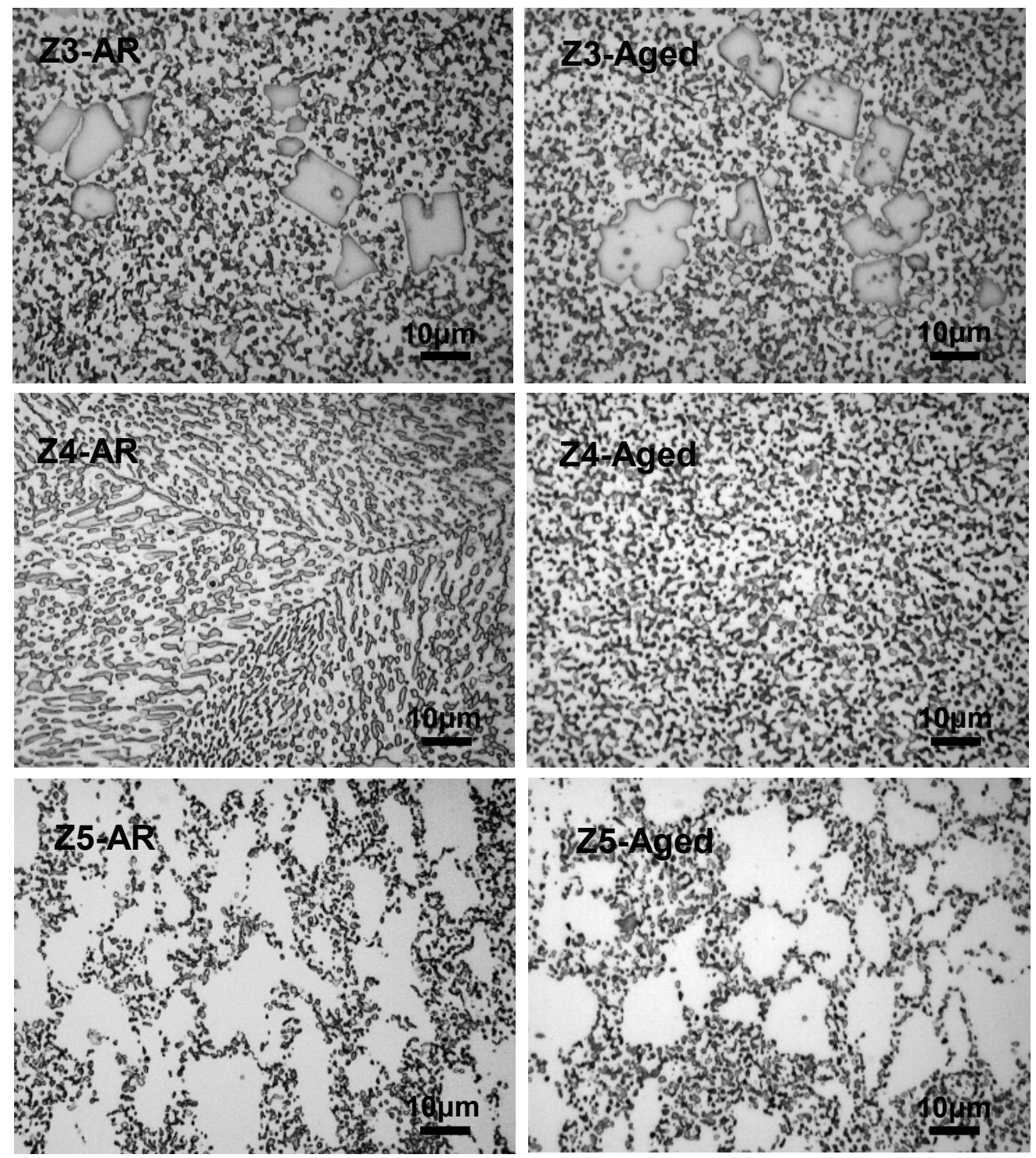

Fig. 11. Optical images of $\mathrm{Z3}, \mathrm{Z4}$ and $\mathrm{Z5}$ in the as-received (AR) state and after thermal aging at $750^{\circ} \mathrm{C}$ for $1800 \mathrm{~h}$.

\subsubsection{High-Cr Ferritic alloys}

The optical images of alloys LT1, LZ1, and LTZ1 are shown in Fig. 12. There are few particles in alloys LT1 and LTZ1, but lots of large particles, primarily identified as Zr nitrides with some oxides in alloy LZ1. Due to the higher Zr content in alloy LZ1 than in alloys LT1 and LTZ1, Zr nitrides and oxides can easily form from liquid phase if $\mathrm{N}$ and/or $\mathrm{O}$ contents are not well controlled to minimal. 
The $\mathrm{Zr}$ nitrides or oxides are precipitated from liquid as large size inclusions that are harmful to mechanical properties. Therefore, only LT1 and LTZ1 are preceded with mechanical testing.
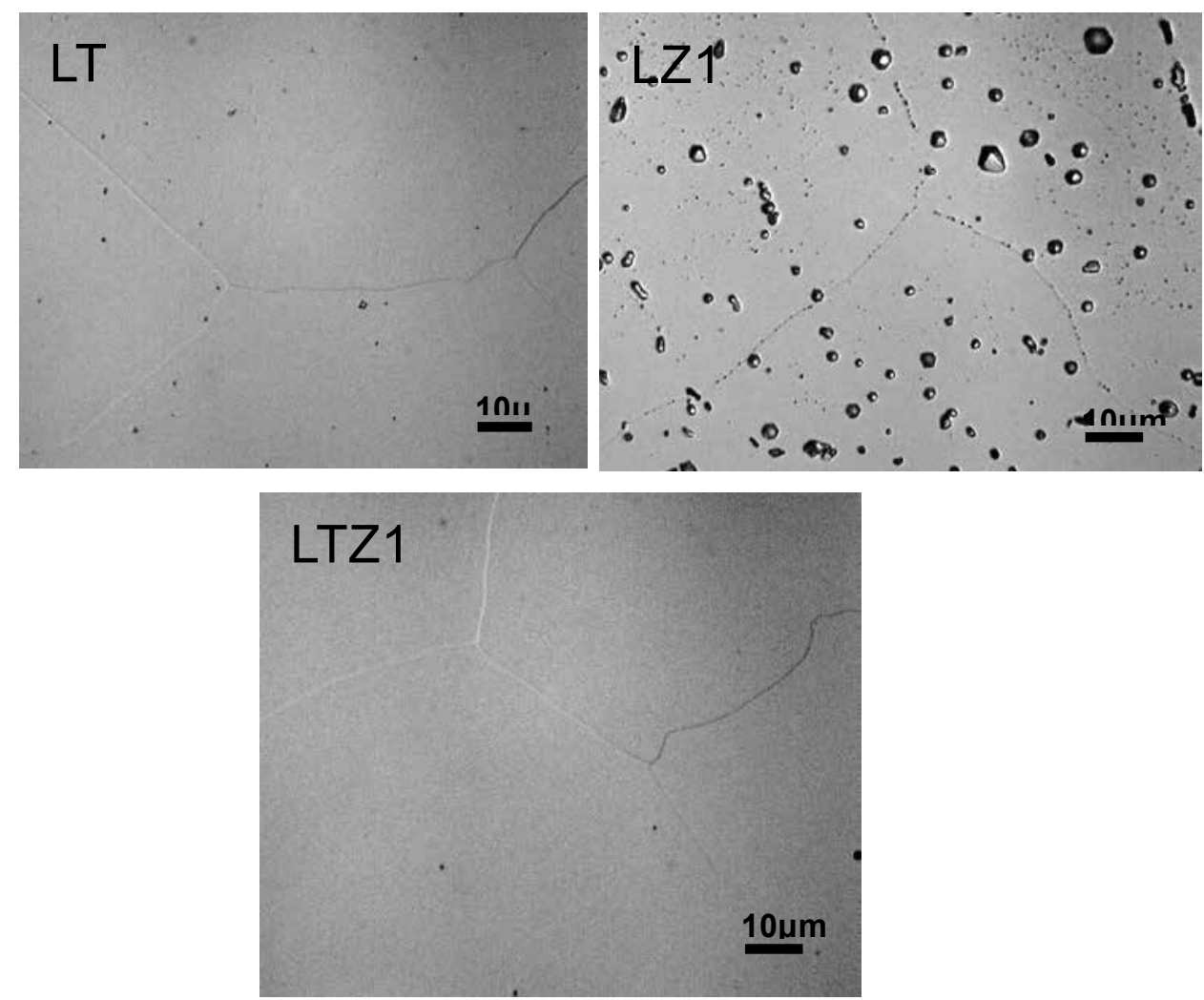

Fig. 12. Optical images of LT1, LZ1, and LTZ1 in the as-received (AR) condition.

The newly designed LNTZ alloy was fabricated at Carpenter Technology with better-controlled N and $\mathrm{O}$ content. Preliminary metallographic characterization shows many particles in a size of 1-2 $\mu \mathrm{m}$, as shown in Fig. 13. The particles are likely Zr-bearing carbides, which will be analyzed using scanning electron microscopy (SEM) with energy dispersive X-ray spectroscopy (EDS). The presence of a large amount and relatively large size of the particles suggests that the carbon content in the alloy may be too high.

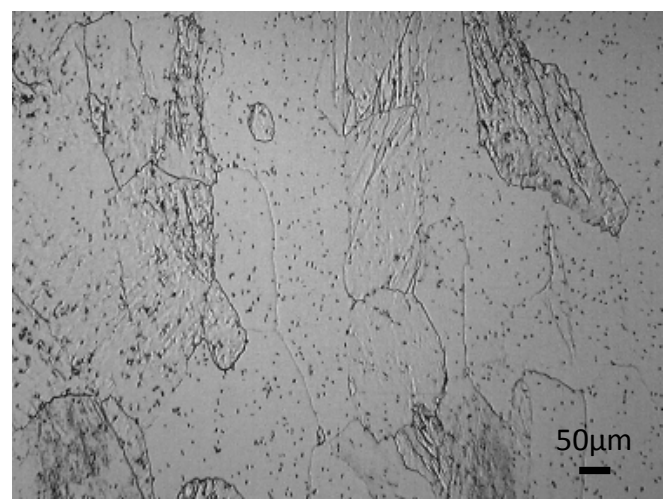

Fig. 13. Optical image of a sample extracted from the as-fabricated heat LNTZ. 
This page intentionally left blank 


\section{EVALUATION OF MECHANICAL PROPERTIES}

\subsection{MECHANICAL TESTING CONDITION}

\section{Microhardness}

Vickers microhardness measurement was conducted on designed alloys using $1 \mathrm{kgf}$ loading $15 \mathrm{~s}$ hold time on the metallographically polished samples. Ten measurements were performed for each sample to get statistic results. The ASTM Standard E384-10, "Standard test method for Knoop and Vickers hardness of materials", was followed during the testing.

\section{Tensile properties}

Type SS-3 specimens were used for tensile testing. The geometry of this type of miniature specimens is shown schematically in Fig. 14. The specimens were machined from the materials with the length of the specimens parallel to the longitudinal direction of the materials. Tensile testing was conducted in air at temperatures from ambient temperature up to $700^{\circ} \mathrm{C}$ following the ASTM Standards E8/E8M-13a, "Standard test methods for tension testing of metallic materials" and E21/E21M-09, “ Standard test methods for elevated temperature tension tests of metallic materials". Tests were performed using an MTS tensile testing system with a load cell possessing $22 \mathrm{kN}$ (5000 lbf) capacity, which is integrated in the load train and placed in the water-cooled zone below the hot zone of the furnace. Tensile testing was performed at a crosshead speed of $0.0076 \mathrm{~mm} / \mathrm{s}(0.018 \mathrm{in} / \mathrm{min})$, corresponding to a nominal strain rate of $\sim 0.0003 \mathrm{~s}^{-1}$. The tensile testing system, load cells, and furnace thermocouples have been routinely calibrated.

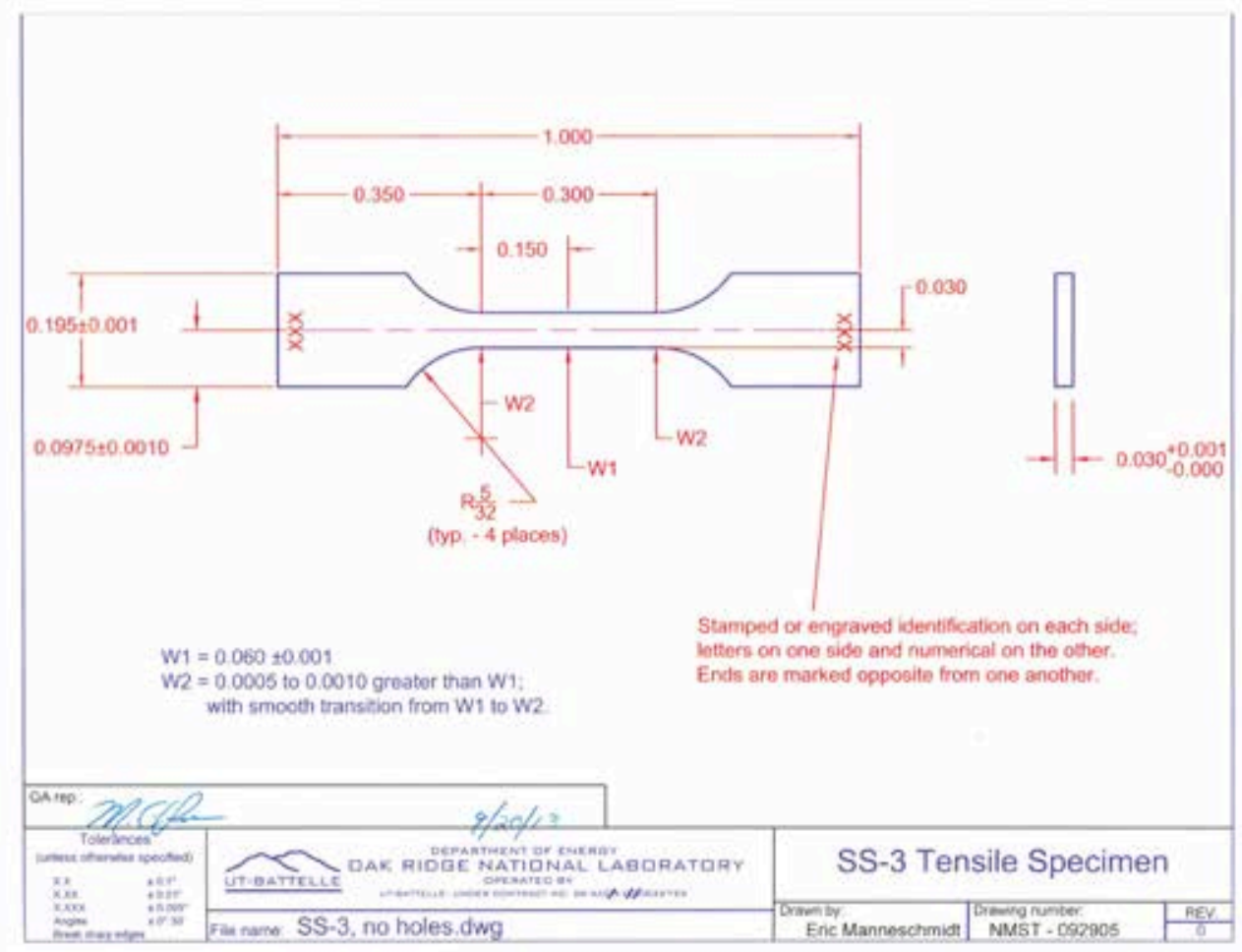

Fig. 14. Specification of type SS-3 specimen. 


\section{Creep resistance}

Type SS-3 specimens using shoulder load was used during the accelerated creep testing in air at $600^{\circ} \mathrm{C}$ and a load of either 300 or $260 \mathrm{MPa}$ using an Applied Test Systems, Inc. Model 2140-CCM115 direct load tester. The ASTM International Designation E139-11, "Standard test methods for conducting creep, creep-rupture, and stress-rupture tests of metallic materials", was referred during the creep testing.

\subsection{CR F/M STEELS}

The Vickers microhardness of Z1, Z2, and T3 are listed in Table 10. The ASTM Standard A335, "Standard specification for seamless ferritic alloy-steel pipe for high-temperature service", requires P/T91 and P/T92 have hardness in a range 196 to 265 HV30. The retreated T3 had a hardness value on the high-bound of the specified hardness. The applied hardness testing load of $1 \mathrm{kgf}$ may result in slightly different hardness values compared to the $30 \mathrm{kgf}$ load specified in the standard. The hardness of alloy Z2 was noticeably lower than the specified low-bound, and thus further testing was not conducted on this alloy.

Table 10. Vickers microhardness of alloys $\mathrm{Z1}, \mathrm{Z2}$ and $\mathrm{T3}$

\begin{tabular}{ccccc}
\hline Alloy & Z1 & Z2 & T3_as-fabricated & T3_retreated \\
\hline Microhardness (HV1) & $200 \pm 3$ & $181 \pm 2$ & $237 \pm 3$ & $269 \pm 5$ \\
\hline
\end{tabular}

The tensile properties of $\mathrm{Z} 1$ and T3_as-fabricated are shown in Fig. 15 in solid diamonds and circles, respectively. The literature data of $\mathrm{P} 91$ heats $\mathrm{MgA}$ and $\mathrm{MgB}$ [27] and $\mathrm{P} 92$ heat MJP [26] tested using regular size samples, together with commercial Grade 92 [28] tested using type SS-3 samples, are also included for comparison. The yield strength and total elongation of alloy $\mathrm{Z} 1$ are comparable to the P91/P92/Gr92 data. In contrast, alloy $\mathrm{T} 3$ in the as-fabricated condition showed moderate (about $10-15 \%$ ) increase in yield stress with slight degradation in total elongation at relatively higher temperatures compared to P91/P92/Gr92. However, the uniform elongation of T3_as-fabricated was noticeably improved over Gr92. In general, alloy T3 in the as-fabricated condition has shown good strength increase with decent ductility. The higher hardness of the retreated alloy T3 is expected to have greater strength than the as-fabricated condition. Tensile specimens of the retreated T3 are being prepared. Tensile testing, as well as accelerated creep-rupture testing, will be pursued once the specimens are received.

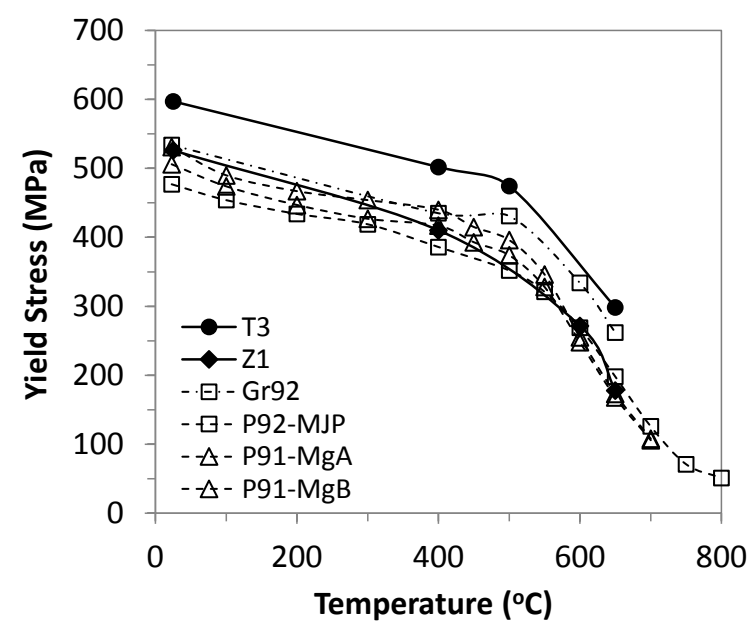

(a) Temperature-dependent yield stress

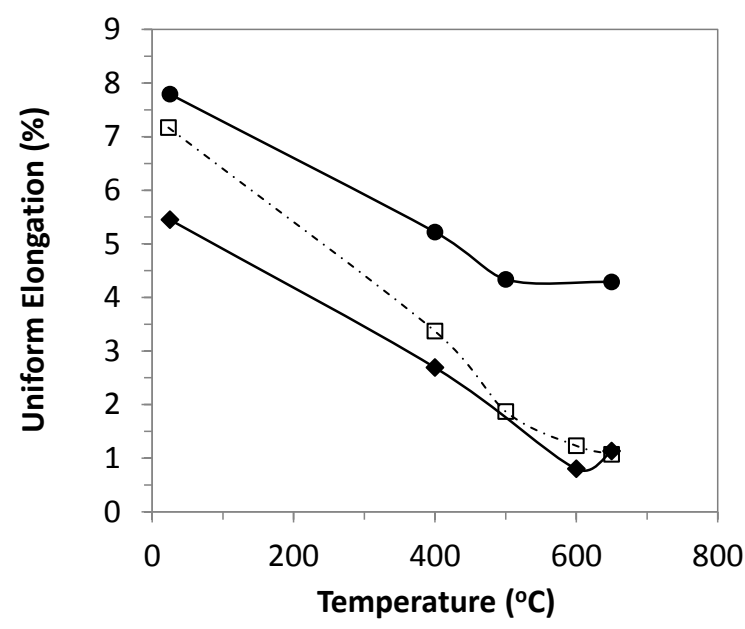

(b) Temperature-dependent uniform elongation 


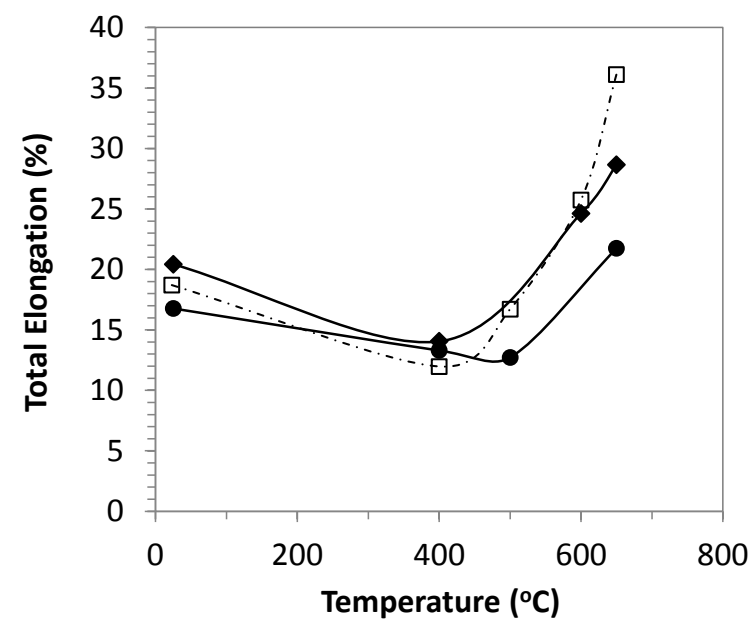

(b) Temperature-dependent total elongation

Fig. 15. Temperature-dependent yield stress, uniform and total elongations of alloys $Z 1$ and $T 3$ compared to reported data of P91, P92, and Gr92.

\subsection{FE2ZR-STRENGTHENED FE-CR-ZR ALLOYS}

The Vickers microhardness data of alloys Z3, Z4, and Z5 are shown in Fig. 16. Alloy Z5 with large ferritic matrix decorated with network of fine $\mathrm{Fe}_{2} \mathrm{Zr}$ particles has the lowest hardness of $230.9 \pm 4.3$ HV1. Alloys $\mathrm{Z3}$ and $\mathrm{Z4}$ with a similar amount of high density dispersive fine $\mathrm{Fe}_{2} \mathrm{Zr}$ particles yield similar hardness of $301.6 \pm 6.3 \mathrm{HV} 1$ of Z3 and $326.4 \pm 5.8 \mathrm{HV} 1$ of Z4. The slightly higher hardness of Z4 compared to Z3 may be attributable to the higher Cr content in Z4 as presented in Section 3.2.2 and the slightly fewer coarse particles in $\mathrm{Z} 4$ as shown in Fig. 10 . The aging at $750^{\circ} \mathrm{C}$ for $1800 \mathrm{~h}$ slightly reduced the hardness of the alloys even though the aging did not introduce distinct microstructures changes as shown in Fig. 11.

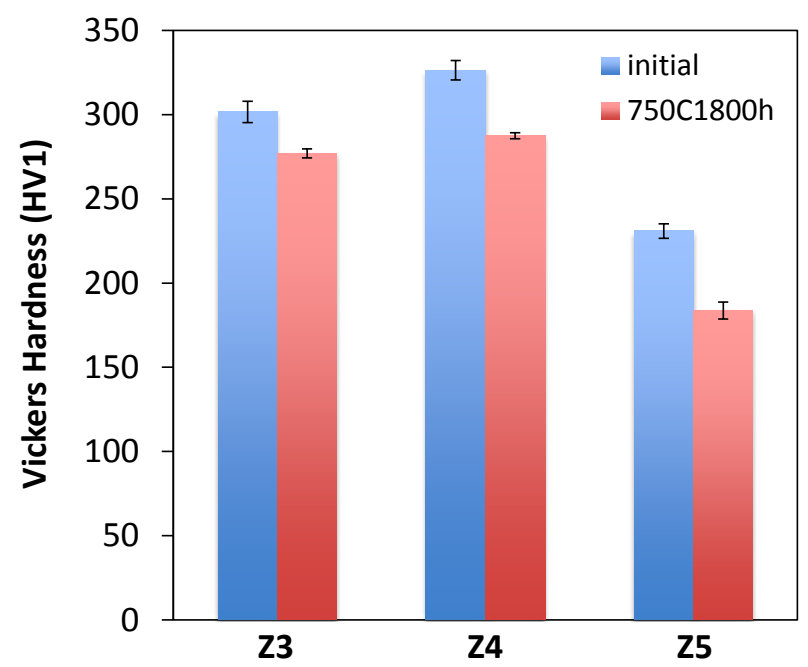

Fig. 16. Vickers microhardness of alloys $\mathrm{Z3}, \mathrm{Z4}$, and $\mathrm{Z5}$ in the as-received and aged conditions.

The tensile properties of alloys Z3, Z4 and Z5 are shown in Fig. 17, compared to literature data of P92 heat MJP. The yield stresses of Z3 are similar to Z4, about $40-60 \%$ higher than P92. Yield 
stresses of Z5 are comparable to P92. Total elongations of the alloys are comparable to Grade 92 at elevated temperatures, as compared to Fig. 14, but poor at room temperature. Alloy Z5 showed relatively better total elongation at room temperature, $12.0 \%$, marginally greater than the ASTM Designation A335 specified minimal total elongation (10.9\%) of Grade 92 with such SS-3 type miniature specimens. Alloys Z3 and Z4 have even lower total elongation, 5.5\% and 4.0\%, respectively, at room temperature. These values are decent for this category of alloys as compared to literature data. For example, a Fe-10Cr-10Zr alloy was reported having plastic strain $\sim 9 \%$ under compression testing at room temperature [29], which would have a lower strain under tensile testing condition. Tensile testing of the samples aged at $750^{\circ} \mathrm{C}$ for $1800 \mathrm{~h}$ is to be conducted to evaluate the aging effect on tensile properties, especially on ductility of the alloys.

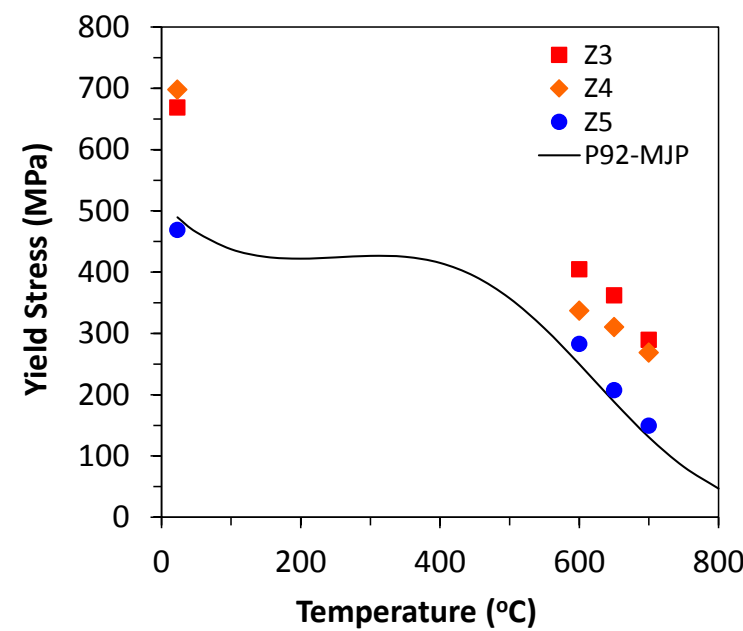

(a) Temperature-dependent yield stress

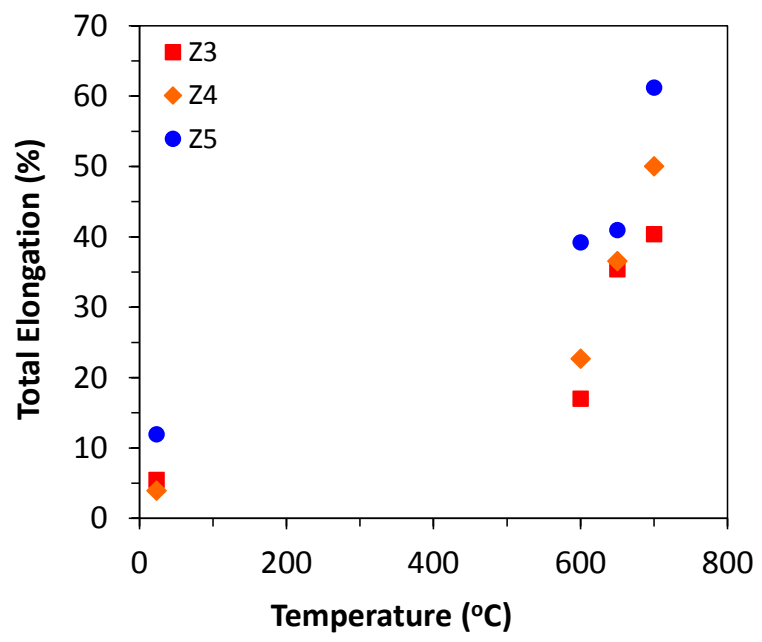

(b) Temperature-dependent yield stress

Fig. 17. Temperature-dependent yield stress and total elongation of alloys $\mathrm{Z3}$, Z4, and $\mathrm{Z5}$.

The creep curves with creep strain as a function of time to rupture for alloys Z3, Z4, and Z5 are shown in Fig. 18, which were tested at $600^{\circ} \mathrm{C}$ and $260 \mathrm{MPa}$. The solid lines and dashed lines are denoted for the as-fabricated and the aged samples, respectively. The data of Grade 92 is also included for comparison. The creep testing indicated different levels of improvement in creep resistance of the alloys in both creep life and ductility over G92.

In the as-fabricated condition, alloy Z4 exhibited the best creep resistance with a creep life about 60 times greater than Grade 92. Alloy Z3 showed slightly less improvement in creep resistance, which was about 45 times over Grade 92. The less Cr content in alloy Z3 compared to that in alloy Z4 did not result in noticeable difference in phase fractions as shown in Fig. 5(a-b), but led to less $\mathrm{Cr}$ in the matrix Bcc_a2 and Laves phase $\mathrm{Fe}_{2} \mathrm{Zr} \_\mathrm{C} 14$ of alloy Z3. The less $\mathrm{Cr}$ content may have resulted in the creep resistance of alloy Z3 inferior to alloy Z4. Alloy Z5 displayed creep life comparable to Grade 92. The noticeably less improvement in creep life of alloy Z5 compared to Grade 92 was directly resulted from the less $\mathrm{Zr}$ content in alloy Z5, and subsequently less Laves phase, than that in alloy Z3 as shown in Fig. 5(a and c).

More importantly, the creep ductility or strain of alloys Z3, Z4, and Z5 was significantly greater than Grade 92, which was as high as more than 2 times of the creep strain of Grade 92. Compared to alloys Z3 and Z4, alloy Z5 exhibited significantly less improvement in creep life and strain over Grade 92. This result may suggest that the Laves phase arrangement in a network shape in alloy Z5 as shown in Fig. 10 may not have strengthening effect as strong as the dispersed ones in alloys Z3 and Z4. Additionally, the Laves phase network may have facilitated crack propagation, resulting in less 
creep strain of alloy Z5 than alloys Z3 and Z4.

The lower creep strain of alloy Z5 is in contrast to the higher tensile strain of alloy Z5 at $600^{\circ} \mathrm{C}$ as shown in Fig. 17. It may indicate that deformation primarily occurred in the matrix and was transferred to the interface between the matrix and Laves phase, leading to failure, during tensile testing. However, the high stress $\left(\sim 0.92\right.$ yield stress of alloy $\mathrm{Z} 5$ at $\left.600^{\circ} \mathrm{C}\right)$ during creep testing resulted in a high strain rate, and consequently quick deformation concentration close to the interface between the matrix and Laves phase. Therefore, developing appropriate processing to interrupt the Laves phase network would improve the strength as well as ductility of alloy Z5.

The aging at $750^{\circ} \mathrm{C}$ for $1800 \mathrm{~h}$ resulted in some increases in creep life with creep strains similar to or slightly less than the as-fabricated condition.

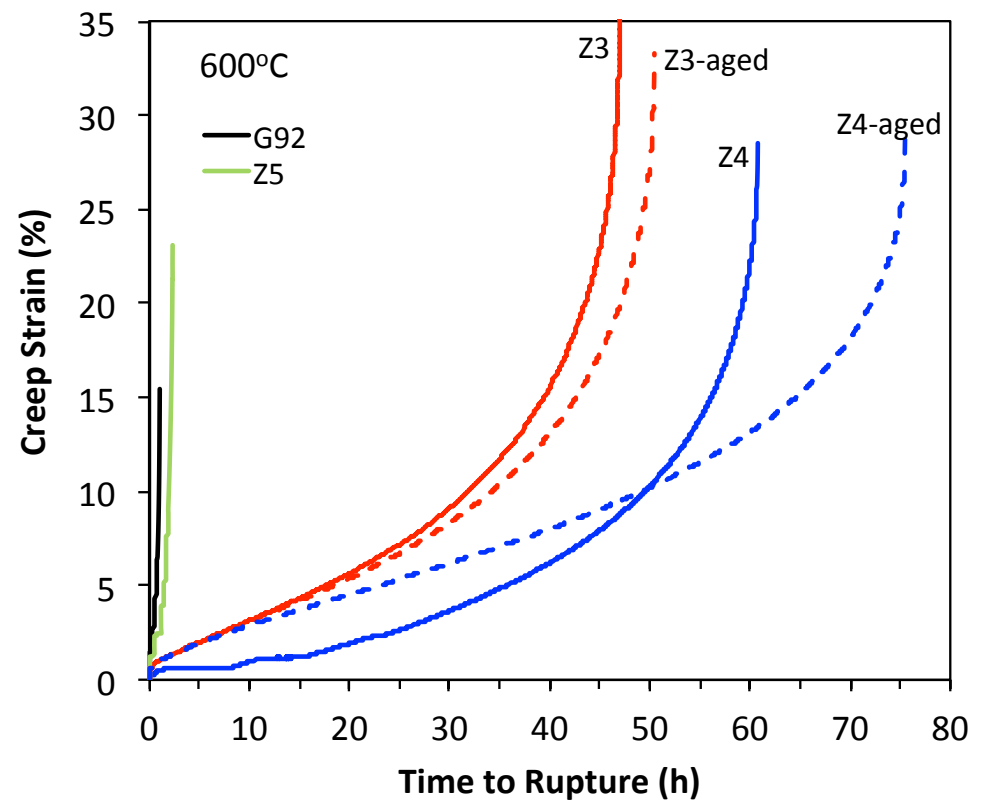

Fig. 18. Creep curves of alloys $\mathrm{Z3}, \mathrm{Z4}, \mathrm{Z5}$ compared to $\mathrm{G92}$ tested at $600^{\circ} \mathrm{C}$ and $260 \mathrm{MPa}$.

\subsection{HIGH-CR FERRITIC STEELS}

In addition to the as-received (AR) condition as described in Table 9, a thermomechanical treatment (TMT) was applied to the $15 \mathrm{Cr}$ ferritic steels LT1 and LTZ1 by $15 \%$ cold rolling followed by aging at $500^{\circ} \mathrm{C}$ for $5 \mathrm{~h}$, denoted as LT1C15 and LTZ1C15, respectively. Alloy LZ1 was not tested because of the large amount of coarse particles in the alloy as shown in Fig. 12. The TMT increased Vickers microhardness of the alloys to $224 \mathrm{HV} 1$ from $177 \mathrm{HV} 1$ of LT1 and to $246 \mathrm{HV} 1$ from $188 \mathrm{HV} 1$ of LTZ1. The TMT-induced hardening was more than $30 \%$.

TEM analysis was conducted to analyze the source of the hardening. Figure 19 shows dark-field images of alloy LT1 in the AR and TMT (LT1C15) conditions, which were taken using the reflections marked with white arrows in the diffraction patterns under the same near [011] two-beam condition. A decent amount of ultrafine precipitates, on the order of $1 \times 10^{22} \mathrm{~m}^{-3}$ with a size less than $\sim 5 \mathrm{~nm}$, exist in the AR (LT1) sample. The TMT significantly refined and increased the amount of precipitates LT1C15 sample, leading to the hardening of this condition compared to the AR one. 


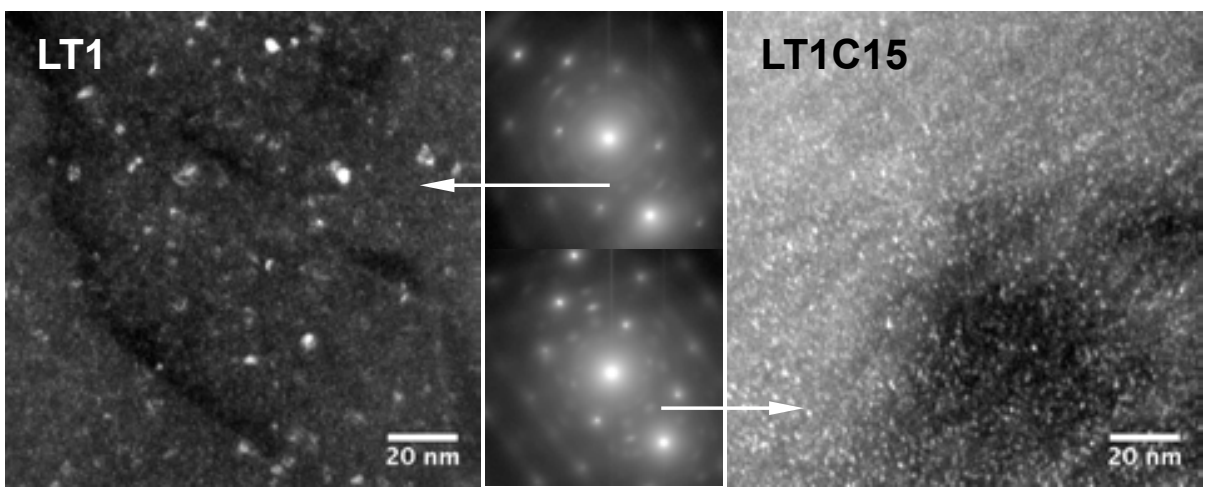

Fig. 19. Dark-field TEM images of alloy LT1 in the AR and TMT (LT1C15) conditions.

Tensile Properties of alloys LT1 and LTZ1 are shown Fig. 20. The alloys' strength is adjustable by TMT, with LT1C15 and LTZ1C15 as examples. Alloys LT1 and LTZ1 in the same condition exhibited similar tensile performance. The yield stresses of the AR condition (LT1 and LTZ1) are relatively low, but still comparable or superior to AISI 304 that is about $250 \mathrm{MPa}$ at room temperature and decreases with increasing temperature to about $100 \mathrm{MPa}$ at $700^{\circ} \mathrm{C}$. The TMT condition (LT1C15 and LTZ1C15) showed significantly increased yield stresses at temperatures below about $500^{\circ} \mathrm{C}$, which are comparable to Grade 91 and 92 as presented in Fig. 15. The increased strength would be primarily attributable to the significantly increased amount of ultrafine precipitates as shown in Fig. 19. The strength enhancement of alloys was compromised with reduction in ductility. The reduced total elongation is comparable to Grade 92 as presented in Fig. 15. Alloy LTZ1C15 samples exhibited occasional low ductility as a result of aggregated Zr-rich oxides/nitrides inclusions as shown in Fig. 21.

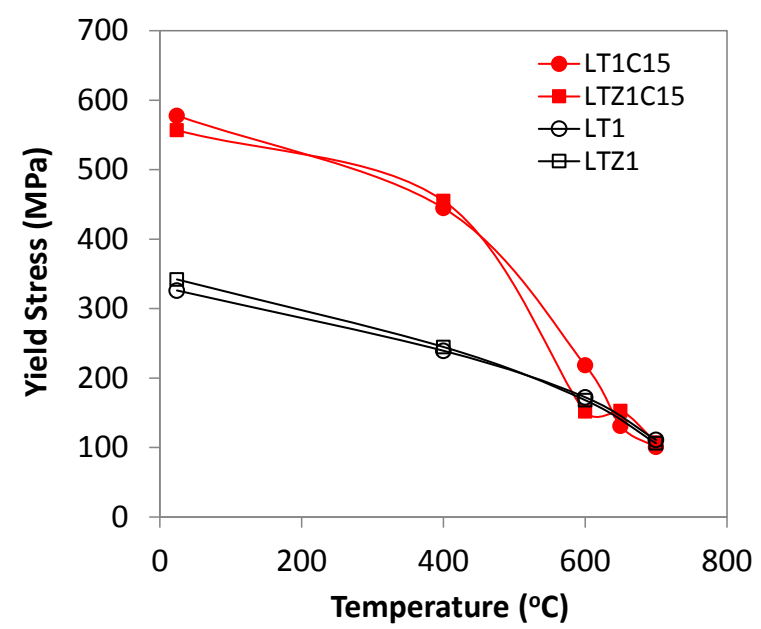

(a) Temperature-dependent yield stress

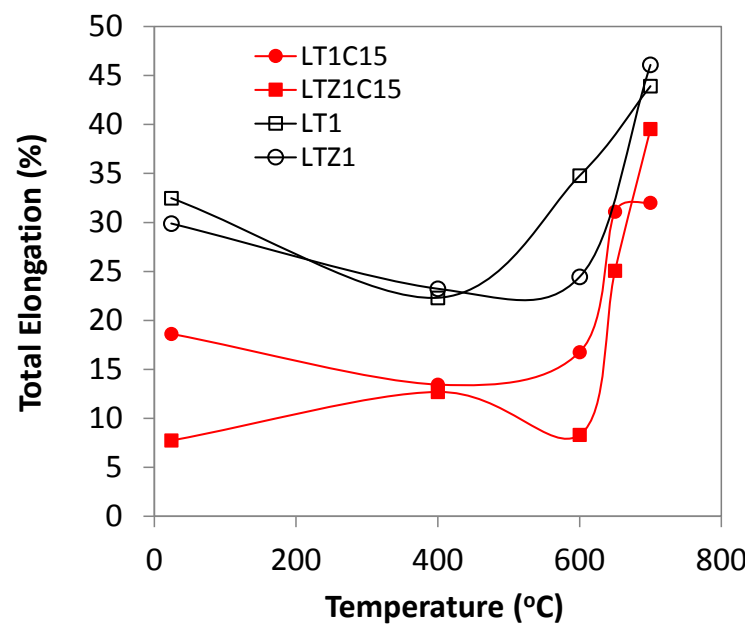

(b) Temperature-dependent total elongation

Fig. 20. Temperature-dependent yield stress and total elongation of alloys LT1 and LTZ1 in the AR and TMT (LT1C15) conditions. 


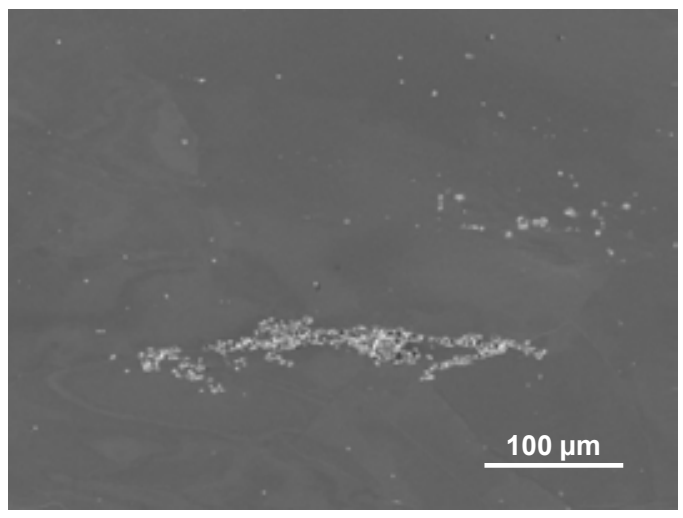

Fig. 21. Aggregated Zr-rich oxides/nitrides inclusions in LTZ1C15 sample.

The Vickers hardness of alloy LNTZ sample was measured to be $179 \pm 9 \mathrm{HV} 1$, comparable to the other high-Cr ferritic steels in this category in the AR condition. Different TMT will be explored to tune the microstructure of the heat. Additionally, this heat will be used to study Laves phase formation kinetics in this category of alloys. 
This page intentionally left blank 


\section{ION-IRRADIATION EXPERIMENT}

\subsection{TANDEM ACCELERATOR ION BEAM}

High-energy ion beams can be produced with a 1.7 MV terminal voltage tandem ion accelerator (Model 5SDH-4, National Electrostatics Corporation Pelletron accelerator) installed at the University of Wisconsin-Madison. The accelerator features dual ion sources for producing negative ions with a sputtering source or using an RF plasma source. This versatility allows for ion beam production of nearly any element (several rare earth elements do not form negative ions). The sources produce ion beam currents ranging from a few tens of $\mu \mathrm{A}$ for the gaseous elements (e.g. He and $\mathrm{N}$ from the $\mathrm{RF}$ source) to $\sim 1 \mu \mathrm{A}$ for elements like silicon used for ion implantation. Negative ions are accelerated to 1.7 MV at the terminal where they undergo electron stripping in a $\mathrm{N}_{2}$ gas chamber. The positive ions are then further accelerated to ground potential at the accelerator exit. Therefore, for an ion with charge $\mathrm{Z}$, the available ion energy is $1.7 \mathrm{MV} \times(\mathrm{Z}+1)$, and the maximum ion energy available is $\sim 5$ $\mathrm{MeV}$ (e.g., for silicon) and mostly depends on the stripping efficiency of the ions into the higher charge states. At the exit from the accelerator tank, a quadropole magnet shapes the beam. Finally a single ion charge state / energy is selected by a switching magnet that sends the beam down to one of 2 beam-lines attached at different angles. Faraday cups and beam profile monitors are also installed to measure beam current and shape respectively. A feedback system maintains the ion beam energy constant to within $+/-500 \mathrm{~V}$. The accelerator operates in a steady state.

The ion irradiation beam line is equipped with a sample stage that incorporates heating capabilities and a reliable method for positioning and securing samples which minimal interference with the monitoring equipment and the ion beam. Samples can be irradiated over a high temperature range from $200^{\circ} \mathrm{C}$ to $1000^{\circ} \mathrm{C}$. Both $3 \mathrm{~mm}$ TEM specimen and bar-shaped coupon samples can be mounted and irradiated. Figure 22 shows the proton irradiation sample stage on left with a sketch of sample mounting on right.
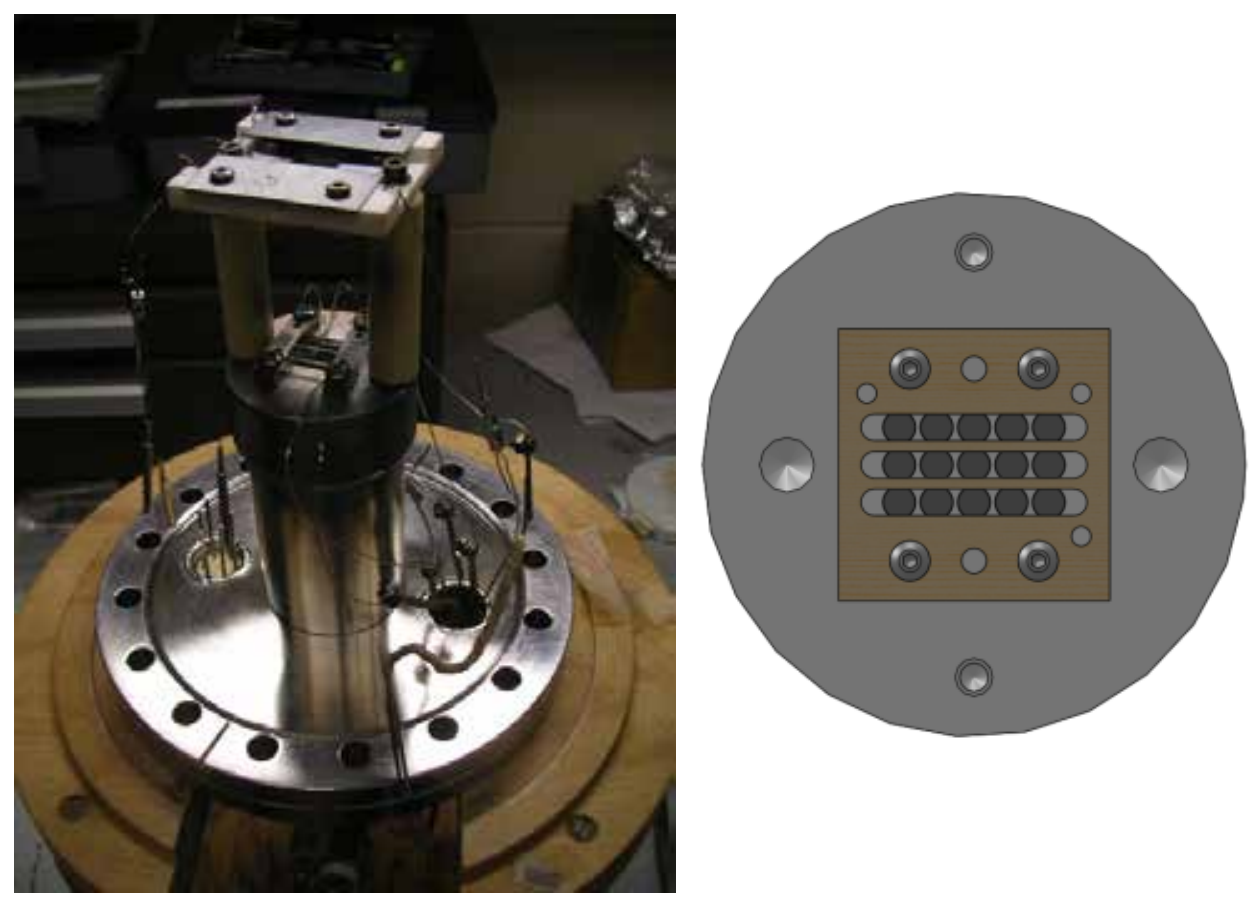

Fig. 22. Proton irradiation sample stage, capable of hosting disc shaped specimens. 


\subsection{ION IRRADIATION EXPERIMENT}

\subsubsection{Materials}

Two ferritic alloys in the category of high-Cr ferritic alloys have delivered to the UW-Madison, namely Fe-15Cr-3W-1.4Ti (denoted as LT1-C3R1-3) and Fe-15Cr-3W-1.4Ti-0.1Zr (denoted as LTZ1-C3R1-3). Samples will be cut into $3 \mathrm{~mm}$ TEM disk and then electro-polished. It is planned to obtain 6 discs from each alloy for various pre- and post-irradiation characterization.

Alloy samples from the other two categories of ferritic alloys will be delivered to the UW-Madison for similar ion irradiation screening.

\subsubsection{Experiment}

Proton irradiation at $2 \mathrm{MeV}$ is planned to be performed on the above-mentioned two alloys at two fluences $(\varphi)$, i.e., $1.1 \times 10^{18} \mathrm{p} / \mathrm{cm}^{2}=0.1 \mathrm{dpa}($ at $10 \mu \mathrm{m})$ and $1.1 \times 10^{19} \mathrm{p} / \mathrm{cm}^{2}=1 \mathrm{dpa}($ at $10 \mu \mathrm{m})$. Figure 23 shows the simulated implantation and damage depth profiles for $\varphi=1.1 \times 10^{19} \mathrm{p} / \mathrm{cm}^{2}$. The displacement threshold energy for all species was assumed to be $40 \mathrm{eV}$. Weighted molar mass of 59 $\mathrm{g} / \mathrm{mol}$ and density of $8.01 \mathrm{~g} / \mathrm{cm}^{3}$ were used in those calculations. The irradiation temperature is planned at $400^{\circ} \mathrm{C}$. Selected samples will be subjected to heavy ion irradiation (e.g., $\mathrm{Fe}^{2+}$ ions) if they exhibit superior performance during proton irradiation screening study.

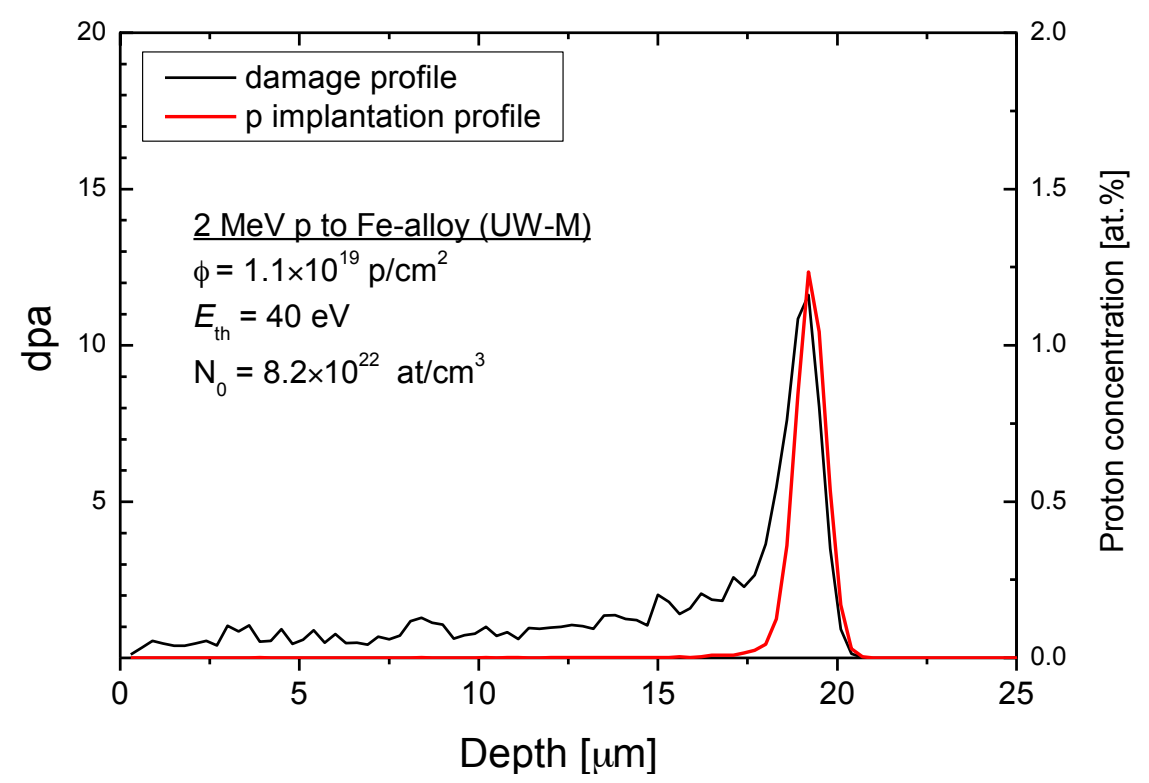

Fig. 23. Damage and proton distributions in Fe-15Cr-3W-1.4Ti irradiated with $1 \mathrm{MeV} p$ to a damage level of $1 \mathrm{dpa}$ at $10 \mu \mathrm{m}$. Calculations were performed using SRIM-2012.03 assuming the displacement threshold energies to be $40 \mathrm{eV}$ for all elements.

The pre- and post-characterization will include:

- XRD - for oxidation, stress, lattice, and phase change

- $\quad$ SEM with EDS and if possible EBSD - general microstructure and radiation-inducedsegregation. FIB will be used to prepare TEM lamellae.

- TEM - defect morphology and distribution

- Microhardness 


\section{SUMMARY AND FUTURE WORK}

This work aims at developing high performance Zr-bearing ferritic steels for applications at elevated temperatures. As described in the previous sections, three categories of alloys have been developed and tested.

One category is 9Cr FM steels such as Z1, showing similar microstructure and mechanical performance as conventional FM steel Grade 92. Further composition adjustment through computational thermodynamics suggested that $\mathrm{Zr}$ has limited working scope in FM alloys because a small amount of $\mathrm{Zr}$ addition would decrease the austenite temperature window and at the same time increase the formation temperatures of the phases that contain $\mathrm{Zr}$. A sufficient temperature range/window of austenite is a prerequisite to form martensite in F/M alloys. After careful composition scoping, alloy T3 has been developed, which showed moderate enhancement in yield strength with slight reduction in total elongation, but noticeable improvement in uniform elongation, as compared to Grade 92. Its microstructure has been furthered refined by different processing to have greater hardness, suggesting higher strength. Its tensile and creep properties will be evaluated soon.

The second category is $\mathrm{Fe}_{2} \mathrm{Zr}$-strengthened ferritic alloys with the Laves phase eutectically formed from liquid, such as alloys Z3 and Z4 having approximately complete eutectic microstructures and alloy Z5 with a small fraction of eutectics. Alloys Z3 and Z4 exhibited excellent strength and ductility combination at elevated temperatures, which exhibited significantly superior creep resistance in both strength and ductility compared to Grade 92 . However, their ductility at room temperature was poor with total elongation as low as $4.0 \%$ of Z4. Compared to Grade 92, alloy Z5 showed comparable strength at temperatures up to testing temperature of $700^{\circ} \mathrm{C}$ with a slightly lower ductility at low temperatures. It is expected that the strength and ductility of alloy Z5 can be improved by interrupting the Laves phase network in the matrix. The aging at $750^{\circ} \mathrm{C}$ for $1800 \mathrm{~h}$ did not result in noticeable coarsening for the Laves phase. The aging slightly decreased the hardness of the alloys, but slightly increased their creep resistance in terms of creep life without sacrificing creep strain at $600^{\circ} \mathrm{C}$.

The third category is high-Cr ferritic alloys with complex Laves phase precipitated from ferrite during lower temperature aging, such as alloys LT1, LZ1, LZT1, and LNTZ. A decent amount of ultrafine precipitates were observed in the matrix of the alloys under standard normalized and aged condition. A TMT significantly refined and increased the amount of the precipitates, leading to the increased hardness and yield strength of the alloys with some reduction in ductility. The preliminary results suggest that the tensile properties of the alloys are controllable to be comparable to Grade 92, in addition to their potential excellent resistance to corrosion and SCC. However, it has been found that controlling impurity contents such as nitrogen and oxygen is critical for this category of alloys due to the high affinity of $\mathrm{Zr}$ to these impurities forming blocky particles from liquid phase, resulting in property degradation. Furthermore, alloy carbon content is also need to be well control because high carbon content would raise the formation temperature of $\mathrm{ZrC}$. A small trial heat has been procured from Carpenter Technology Corporation, which showed well-controlled nitrogen and oxygen. Further development and testing of the alloy will be pursued.

In summary, the major accomplishments during the first year of this project are:

1) Thermodynamic database of the Fe-C-Cr-Mo-Nb-Ti-W-Zr system has been developed using the Calphad approach based on the experimental phase equilibrium and thermodynamic property data. 
2) Thermodynamic models of phases in the Fe-C-Cr-Mo-Nb-Ti-W-Zr system have been integrated into the OCTANT (ORNL Computational Thermodynamics for Applied Nuclear Technology) database, which allows rapid screening on phase stabilities of designed alloys.

3) Three design routes of $\mathrm{Zr}$-bearing ferritic steels have been explored, i.e., 9Cr FM steels, $\mathrm{Fe}_{2} \mathrm{Zr}$-strengthened $\mathrm{Fe}-\mathrm{Cr}-\mathrm{Zr}$ alloys with the Laves phase eutectically formed from liquid, and high- $\mathrm{Cr}(15 \mathrm{Cr})$ ferritic alloys with the strengthening complex Laves phase precipitated from ferritic matrix during aging.

4) The preliminary results of the developed three categories of alloys exhibited superior or comparable tensile and creep performance, compared to Grade 92 steels. To obtain superior performance of $\mathrm{Zr}$-bearing alloys, it is critical to minimize the impurity content of nitrogen and oxygen. Additionally, appropriate TMTs have shown capability of optimizing microstructures for property improvement.

5) Ion irradiation experiments using proton have been initiated to screen the radiation resistance of the selected new alloys and study the effect of $\mathrm{Zr}$ alloying on radiation resistance. 


\section{REFERENCES}

1. N. Baluc, On the potentiality of using ferritic/martensitic steels as structural materials for fusion reactors, FT/1-1Rb

2. H. Mimura, M. Ohgami, H. Naoi, T. Fujita, Properties of $9 \mathrm{Cr}-1.8 \mathrm{~W}$ steel with high creep strength for USC boiler piping and tubing applications, in: D. Coutsouradis (Eds.), Materials for Advanced Power Engineering, Kluwer Academic Publishers, The Netherlands, 1994, pp. 361.

3. B. Raj, M. Vijayalakshmi, Ferritic steels and advanced ferritic-martensitic steels, in: R.J.M. Konings, T.R. Allen, R.E. Stoller, S. Yamanaka, Comprehensive Nuclear Materials, Elsevier, 2012.

4. K. Maruyama, K. Sawada, J. Koike, Strengthening mechanisms of creep resistant tempered martensitic steel, ISIJ International 41 (2001) 641-653.

5. L. Tan, T.S. Byun, Y. Katoh, L.L. Snead, Stability of MX-type strengthening nanoprecipitates in ferritic steels under thermal, stress, and ion irradiation, in preparation.

6. D.G. Morris, M.A. Munoz-Morris, L.M. Requejo, Acta Materialia 54 (2006) 2335-2341.

7. N. Shigenaka, S. Ono, Y. Isobe, T. Hashimoto, H. Fujimori, S. Uchida, Effect of zirconium addition to austenitic stainless steels on suppression of radiation induced chromium segregation at grain boundaries under ion irradiation, Journal of Nuclear Science and Technology 33 (1996) 577-581.

8. M.J. Hackett, J.T. Busby, M.K. Miller, G.S. Was, Effects of oversized solutes on radiationinduced segregation in austenitic stainless steels, Journal of Nuclear Materials 389 (2009) 265278.

9. L. Kaufman, B. Uhrenius, D. Birnie, K. Taylor, Coupled pair potential, thermochemical and phase-diagram data for transition-metal binary-systems .7., CALPHAD 8 (1984) 25-66.

10. N. Saunders and A.P. Miodownik, CALPHAD (Calculation of Phase Diagrams): A Comprehensive Guide ( $1^{\text {st }}$ Ed.), Elsevier, New York, 1998.

11. Muggianu, Yves M., Michele Gambino, and Jean P. Bros, Enthalpies of formation of liquid alloys bismuth-gallium-tin at 723.deg.K. Choice of an analytical representation of integral and partial excess functions of mixing, Journal de Chimie Physique et de Physico-Chimie Biologique 72 (1975) 83-91.

12. http://www.computherm.com

13. http://www.thermocalc.com

14. Y. Yang, L. Tan, H. Bei, J.T. Busby, Thermodynamic modeling and experimental study of the FeCr-Zr system, Journal of Nuclear Materials 441 (2013) 190-202.

15. F. Stein, G. Sauthoff, M. Palm, Experimental determination of intermetallic phases, phase equilibria, and invariant reaction temperatures in the Fe-Zr system, Journal of Phase Equilibia 23 (2002) 480-494.

16. V.S. Sudavtsova, V.P. Kurach, G.I. Batalin, Thermochemical properties of molten binary Fe-(Y, $\mathrm{Zr}, \mathrm{Nb}, \mathrm{Mo}$ ) alloys, Russian Metallurgy 3 (1987) 59-60.

17. O.Y. Sidorov, M.G. Valishev, Y.O. Esin, P.V. Geld, Enthalpy of formation of molten Zr-Fe, Russian Metallurgy 6 (1988) 19-21.

18. H. Wang, R. Luck, B. Predel, Calorimetric determination of the enthalpy of mixing of liquid ironzirconium alloys, Zeitschrift fur Metallkunde 81 (1990) 843-846.

19. M. Rosnerkuhn, J.P. Qin, K. Schaefers, U. Thiedemann, M.G. Frohberg, Temperaturedependence of the mixing enthalpy and excess heat-capacity in the liquid-system iron-zirconium, Zeitschrift fur Metallkunde 86 (1995) 682-685.

20. P.R. Ohodnicki, Jr., N.C. Cates, D.E. Laughlin, M.E. McHenry, and M. Widom, Ab initio theoretical study of magnetization and phase stability of the $(\mathrm{Fe}, \mathrm{Co}, \mathrm{Ni})_{23} \mathrm{~B}_{6}$ and $(\mathrm{Fe}, \mathrm{Co}, \mathrm{Ni})_{23} \mathrm{Zr}_{6}$ structures of $\mathrm{Cr}_{23} \mathrm{C}_{6}$ and $\mathrm{Mn}_{23} \mathrm{Th}_{6}$ prototypes, Physical Review B 78 (2008) 144414. 
21. P. Barberis, N. Dupin, C. Lemaignan, A. Pasturel, amd J. M. Grange, Microstructure and phase control in $\mathrm{Zr}-\mathrm{Fe}-\mathrm{Cr}$-Ni alloys: thermodynamic and kinetic aspects, Journal of ASTM International 2 (2005) JAI12771.

22. C. Servant, C. Gueneau, I. Ansara, Experimental and thermodynamic assessment of the $\mathrm{Fe}-\mathrm{Zr}$ system, Journal of Alloys and Compounds 220 (1995) 19-26.

23. M. Jiang, K. Oikawa, T. Ikeshoji, L. Wulff, K. Ishida, Thermodynamic calculaitons of Fe-Zr and Fe-Zr-C systems, Journal of Phase Equilibria 22 (2001) 406-417.

24. C. Guo, Z. Du, C. Li, B. Zhang, M. Tao, Thermodynamic description of the Al-Fe-Zr system, CALPHAD 32 (2008) 637-649.

25. OCTANT-ORNL Computational Thermodynamics for Applied Nuclear Technology, Ying Yang, Oak Ridge National Lab, 2012-2013

26. NIMS Creep Data Sheet No. 48A, 2012

27. NRIM Creep Data Sheet No. 43, 1996

28. L. Tan, D.T. Hoelzer, J.T. Busby, M.A. Sokolov, R.L. Klueh, Microstructure control for high strength 9Cr ferritic-martensitic steels, Journal of Nuclear Materials 422 (2012) 45-50.

29. S. Scudino, P. Donnadieu, K.B. Surreddi, K. Nikolowski, M. Stoica, Microstructure and mechanical properties of Laves phase-reinforced $\mathrm{Fe}-\mathrm{Zr}$-Cr alloys, Intermetallics 17 (2009) 532539. 


\section{INTERNAL DISTRIBUTION}

1. J.T. Busby

2. R.K. Nanstad

3. L. Tan
4. Y. Yang

5. S.J. Zinkle

\section{EXTERNAL DISTRIBUTION}

6. T.R. Allen, Univ. of Wisconsin

7. S. Lesica, DOE

8. K. Sridharan, Univ. of Wisconsin 